\title{
Consequences of combining siRNA-mediated DNA methyltransferase 1 depletion with 5-aza-2'-deoxycytidine in human leukemic KG1 cells
}

\author{
Stéphane Vispé $^{1}$, Arthur Deroide ${ }^{1}$, Emeline Davoine ${ }^{1}$, Cécile Desjobert $^{1}$, Fabrice \\ Lestienne $^{2}$, Lucie Fournier ${ }^{1}$, Natacha Novosad ${ }^{1}$, Sophie Bréand ${ }^{3}$, Jérôme Besse ${ }^{3}$, \\ Florence Busato ${ }^{4}$, Jörg Tost ${ }^{4}$, Luc De Vries², Didier Cussac ${ }^{2}$, Joëlle Riond ${ }^{1}$, Paola \\ B. Arimondo ${ }^{1}$ \\ ${ }^{1}$ Unité de Service et de Recherche n³388 CNRS-Pierre Fabre, ETaC Epigenetic Targeting of Cancer, CRDPF, Toulouse, France \\ ${ }^{2}$ Molecular and Cellular Biology Department, Centre de Recherche Pierre Fabre, Castres, France \\ ${ }^{3}$ Informatique de Recherche (Bioinformatics and Statistics), Centre de Recherche Pierre Fabre, Castres, France \\ ${ }^{4}$ Laboratory for Epigenetics and Environment, Centre National de Génotypage, CEA-Institut de Génomique, Evry, France
}

Correspondence to:

Stéphane Vispé, e-mail: stephane.vispe@pierre-fabre.com

Paola B. Arimondo, e-mail: paola.arimondo@etac.cnrs.fr

Keywords: leukemia, DNA methylation, DNMT, 5-aza-2'-deoxycytidine, DNA damage

Received: December 28, $2014 \quad$ Accepted: February 08, $2015 \quad$ Published: March 20, 2015

\section{ABSTRACT}

5-azacytidine and 5-aza-2'-deoxycytidine are clinically used to treat patients with blood neoplasia. Their antileukemic property is mediated by the trapping and the subsequent degradation of a family of proteins, the DNA methyltransferases (DNMT1, DNMT3A, and DNMT3B) leading to DNA demethylation, tumor suppressor gene re-expression and DNA damage. Here we studied the respective role of each DNMT in the human leukemia KG1 cell line using a RNA interference approach. In addition we addressed the role of DNA damage formation in DNA demethylation by 5-aza-2'-deoxycytidine. Our data show that DNMT1 is the main DNMT involved in DNA methylation maintenance in KG1 cells and in mediating DNA damage formation upon exposure to 5-aza-2'-deoxycytidine. Moreover, KG1 cells express the DNMT1 protein at a level above the one required to ensure DNA methylation maintenance, and we identified a threshold for DNMT1 depletion that needs to be exceeded to achieve DNA demethylation. Most interestingly, by combining DNMT1 siRNA and treatment with low dose of 5-aza-2'-deoxycytidine, it is possible to uncouple DNA damage formation from DNA demethylation. This work strongly suggests that a direct pharmacological inhibition of DNMT1, unlike the use of 5-aza-2'-deoxycytidine, should lead to tumor suppressor gene hypomethylation and re-expression without inducing major DNA damage in leukemia.

\section{INTRODUCTION}

In recent years, epigenetic modifications in cancer have been largely investigated and have successfully led to the development of novel anticancer therapies aimed at reversing aberrant modification patterns, among which DNA methylation at cytosines in $\mathrm{CpG}$ dinucleotides is probably the best studied $[1,2]$. In normal cells, these $\mathrm{CpG}$ are generally methylated, protecting the cells from
DNA rearrangement, while in the promoters of tumor suppressor genes (TSG) the $\mathrm{CpG}$ grouped in structures called $\mathrm{CpG}$ islands (CGIs) are mostly unmethylated. But in many cancer cells, bulk DNA becomes largely unmethylated, allowing for the re-expression of embedded sequences associated with genomic instability. At the same time promoters of many TSG become hypermethylated, associated with the silencing of the corresponding genes [3]. Such deregulation has been used to identify and 
develop DNA methylation inhibitors, among which two "epidrugs" have been approved to treat myelodysplasic syndromes (MDS), Acute Myeloid Leukemia (AML) and Chronic MyeloMonocytic Leukemia (CMML), namely 5-aza-2'-deoxycytidine (Dacogen ${ }^{\circledR}$, hereafter named DAC) and 5-aza-2'cytidine (Vidaza ${ }^{\mathrm{TM}}$ ) [4-7]. These cytosine analogs target a family of proteins, called DNA Methyltransferases or DNMTs, responsible for the transfer of a methyl group onto a cytosine in the context of a $\mathrm{CpG}$ dinucleotide. But their chemical instability translates into poor pharmacokinetics properties in human, and a more stable analogue, i.e. SGI-110, is presently being evaluated in clinical trials, both for blood and solid tumors [8-10]. Regarding their molecular mechanism of action, these nucleoside analogs incorporate into DNA, act as cytosine decoy and trap irreversibly the various DNMTs, inducing their proteasome-dependent degradation [11-14]. This loss of the DNMT enzymes then leads to passive demethylation of silenced TSGs associated with their reexpression, ultimately leading to cell growth arrest and cell death. Moreover, the formation of DNMT adducts in DAC-enriched DNA was shown to generate DNA damage in various solid cancer cell lines, and particularly DNA breaks inducing $\gamma \mathrm{H} 2 \mathrm{AX}$ phosphorylation [15-18]. Such lesions can contribute to active DNA demethylation through excision of methylated cytosines $(\mathrm{mC})$ from the DNA, which are subsequently repaired and replaced by unmethylated cytosines, in addition to inducing cell cycle arrest in the G2/M phases and loss of viability. These mechanisms are not selective for a specific DNMT, but rather involve all DNMTs acting on DNA.

Among the DNMTs, DNMT1 is normally referred to as the methylation maintenance enzyme, mainly ensuring the faithful transmission of the $\mathrm{CpG}$ methylation patterns from the parent to the daughter cells upon division. DNMT3A and 3B are involved in de novo methylation, particularly during development [19]. Nevertheless some reports suggest that DNMT3B could play a role in methylation maintenance as well $[20,21]$. Still the respective role of each DNMT in promoting and maintaining the oncogenic transformation is largely unknown. Several articles have reported the use of RNA interference or knockout approaches to address the relative importance of each DNMT on DNA methylation, gene expression and cell proliferation, but essentially in solid tumors. For instance, the knockout of DNMT1 or DNMT3B alone in the human colon cancer cell line HCT116 does not impact DNA methylation, while their concomitant invalidation induces profound hypomethylation leading to a minimal methylation footprint on DNA [22, 23]. In the same cell line, Robert and coll. found that DNMT1 depletion by siRNA induces CDKN2A demethylation [24], while another group using the same approach in the same cell line did not observe any demethylation of this gene [21]. DNMT3B was also shown to be required for the maintenance of DNA hypermethylation in cervical cancer cells [25]. In breast cancer cells, Chick and coll. demonstrated that the concomitant downregulation of DNMT1/3A/3B proteins lead to inhibition of cell growth and DNA hypomethylation associated with gene reexpression [26]. Interestingly, DAC leads to a different gene expression pattern compared to the siRNA-mediated depletion of all three DNMTs, suggesting potential additional targets for DAC-mediated phenotypes. Thus, despite a consistent number of studies, the importance of each DNMT for cancer maintenance still needs to be clarified. Noteworthy, it seems to depend on the cancer type, and, since all these data come from solid tumors, when FDA-approved demethylating agents are used in MDS and AML, we chose to explore the role of each DNMT in this pathology. To the best of our knowledge, concerning hematological cancers, the recent work from Peters and coll. is unique in relating the oncogenic potential of DNMT1 in a mouse model of MYC-induced T-cell lymphoma [27]. Here we addressed the role of each DNMT on the DNA hypermethylation and gene repression of TSG in the human AML KG1 model cell line, by using the RNA interference approach and compared it to the effect induced by DAC.

Our data show that (i) DNMT1 is the main methyltransferase involved in the maintenance of global and TSG promoter-specific (TP73, CDH1 and $C D K N 2 B)$ DNA hypermethylation in KG1 cells; (ii) DNA damage formation can be dissociated from DNA demethylation activity in cells exposed to DAC; (iii) KG1 cells express DNMT1 protein at a level largely superior to the one required to ensure DNA methylation maintenance; (iv) a threshold must be bypassed in order to trigger global DNA hypomethylation and specific DNA demethylation of tumor suppressor genes, and (v) TP73 mRNA re-expression by DAC requires, in addition to demethylation of its promoter, another molecular event, potentially DNA damage.

\section{RESULTS}

\section{SiRNA-mediated downregulation of each DNMT (DNMT1, 3A, and 3B) or concomitantly of the three together does not induce DNA demethylation, unlike the DNA demethylating agent DAC}

First, the expression levels of DNMT1, 3A and 3B and their variant types were assessed in three blood cancer model cell lines, namely KG1, HL60 and Karpas299. All three DNMTs are expressed at the mRNA level (Supplementary Figure S1). However, only KG1 expresses relatively high levels of all DNMTs and especially of DNMT3B, compared to the other cell lines (Supplementary Figure S1 and Table S1). In particular, KG1 cells mainly express variant 6 of $D N M T 3 B$ and several mRNA variants of DNMT3A (Supplementary Table S1). Because KG1 
expresses all three DNMTs at high levels and it is known to possess several hypermethylated TSG promoters, we chose it as in vitro human leukemia model to address the respective role of each DNMT in the maintenance of DNA methylation homeostasis.

Second, each DNMT was downregulated by RNA interference (siRNA) and DAC was used as the reference DNA demethylating agent. Each designed siRNA depleted its corresponding DNMT - although to a different extent without significantly affecting the expression of the other proteins (Supplementary Figure S2). When the three siRNAs were combined together, DNMT1/3A/3B were all depleted to similar levels, with mean residual percentage amounts of $45 \%( \pm 17 \%), 57 \%( \pm 16 \%)$, and $17 \%( \pm 10 \%)$ for DNMT1, 3A and 3B, respectively (Figure 1a). Upon treatment with $100 \mathrm{nM}$ DAC daily during 3 days, DNMT1, 3A, and 3B proteins were depleted down to $20 \%( \pm 17 \%), 39 \%( \pm 9 \%)$ and $43 \%( \pm 12 \%)$, respectively. Noteworthy, the low dose of 10 nM DAC efficiently depleted each DNMT down to $30 \%( \pm 13 \%), 47 \%( \pm 19 \%)$ and $65 \%( \pm 23 \%)$ for DNMT1, 3A and $3 \mathrm{~B}$ respectively. The depletion induced by the siRNAs was slightly weaker compared to that induced by DAC for DNMT1 and DNMT3A but stronger for DNMT3B. Next we addressed the impact of these treatments on global DNA methylation (Figure 1b) and observed that DAC induced a significant DNA demethylation, while the downregulation by siRNA of either DNMT1, DNMT3A or DNMT3B individually or together did not affect significantly DNA methylation (Figure 1b, and data not shown for individual siRNA). Interestingly, the lowest dose used of DAC, $10 \mathrm{nM}$, hardly affected the level of global DNA methylation, although depleting already strongly the DNMTs. The impact of these DNMT depletion on the methylation of the promoters of three TSGs, TP73, $C D K N 2 B$, and $C D H 1$, was investigated using Methyl-Specific High Resolution Melting (MS-HRM). As for global DNA methylation, DAC induced a dose-dependent demethylation of all three promoters, while siRNA-mediated depletion of the DNMTs did not show any significant effect (Figure 1c and Supplementary Figure $\mathrm{S} 3$ for $C D H 1$ and $C D K N 2 B$ ). Since three days of $D N M T$ downregulation were not sufficient to observe an impact on DNA methylation, we double-transfected the siRNAs to increase the efficiency and duration of DNMT depletion. Only siRNAs targeting $D N M T 1$ and $3 B$ were used since they were more efficient than DNMT3A siRNA. Despite this longer downregulation period, promoter methylation of the three TSG was not affected, in contrast to DAC that led to a significant demethylation $72 \mathrm{~h}$ post-treatment and up to 4 days after discontinuing the DAC treatment (Supplementary Figure S4). Since it has been shown in the human colon cancer cell line HCT116 that downregulation of DNMT1 by siRNA induced a demethylation of the promoter of CDKN2A [24], we tested in HCT116 the same DNMT1
siRNA that we used in KG1. In this solid tumor cell line, a strong depletion of the DNMT1 protein was obtained ( $>95 \%)$ similar to that obtained with $30 \mathrm{nM}$ and higher concentrations of DAC (Figure 2a). This strong depletion induced a significant demethylation of the TP73 promoter (Figure 2b) and of the CDKN2A, IRF8 and $R A S S F 1 A$ promoters (data not shown), in agreement with the previous results. In addition, the strong depletion of the DNMT1 protein by the siRNA induced also a global demethylation at the LINE-1 repeated elements. Interestingly, lower doses of DNMT1 siRNA that induced a partial $(40 \%)$ depletion of the protein had no global demethylating effect (Supplementary Figure S5). Consequently, we hypothesized that the partial siRNAdependent DNMT downregulation (55\% for DNMT1, $43 \%$ for DNMT3A and $83 \%$ for DNMT3B proteins) observed in KG1 may be the limiting factor for an efficient promoter demethylation. To explore this hypothesis and increase the depletion of DNMT, we combined the siRNA approach with $10 \mathrm{nM}$ of DAC, a dose inducing depletion of all three DNMT, but without a marked impact on DNA methylation (Figure 1).

\section{Combining DNMT1 siRNA and DAC treatment increases DNMT1 depletion and induces global DNA demethylation}

The combination of siRNAs targeting each DNMT with $10 \mathrm{nM}$ DAC increased the level of DNMT1 depletion (>95\%), but not of DNMT3A and 3B depletion (Figure $3 \mathrm{a}$ and data not shown). Noteworthy, the control siRNA (Luc) had no modifying effect on the DNMT level, either used alone or combined with the increasing doses of DAC. We thus pursued our investigations with the DNMT1 siRNA combined with DAC and used two different siRNAs, namely 1(6) and 1(7), targeting distant regions on the DNMT1 mRNA sequence (see Materials and Methods). Both siRNAs alone induced similar depletion of the protein (Figure 3a), namely around $73-86 \%$, and more than $95 \%$ when combined with 10 or $100 \mathrm{nM}$ of DAC (Figure 3a). Then the impact of this DNMT1 depletion on global DNA methylation was measured. As shown in Figure 3b, combining DNMT1 siRNA (1(6) or 1(7)) with $10 \mathrm{nM}$ DAC induced a significant demethylation, similar to that induced by higher doses of DAC alone, 30 and 100 $\mathrm{nM}$ (Figure $3 \mathrm{~b}$ ). This was not observed with the siRNAs against $D N M T 3 A$ and $3 B$ (data not shown). This synergy was increased in combination with $100 \mathrm{nM}$ DAC. These results were confirmed by bisulfite conversion followed by pyrosequencing of the LINE-1 and AluSc highly repeated sequences used as surrogate markers for global DNA methylation (Figure 3c and 3d). Thus an increase in the depletion of DNMT1 by combining the siRNA approach and low doses of DAC is able to demethylate DNA in KG1 cells. Since previous works suggested a potential 
DNMT1

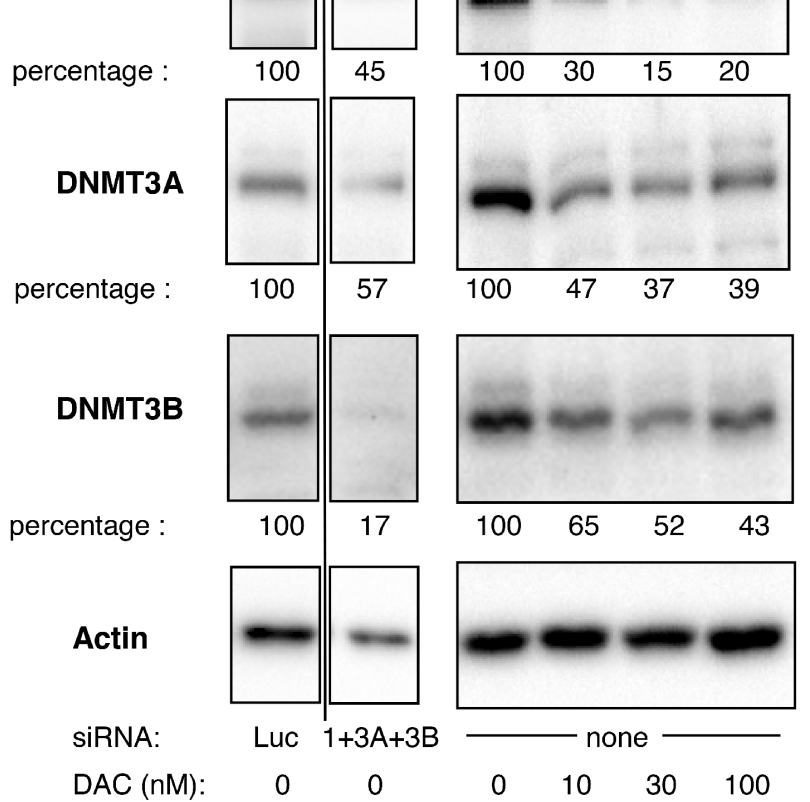

b

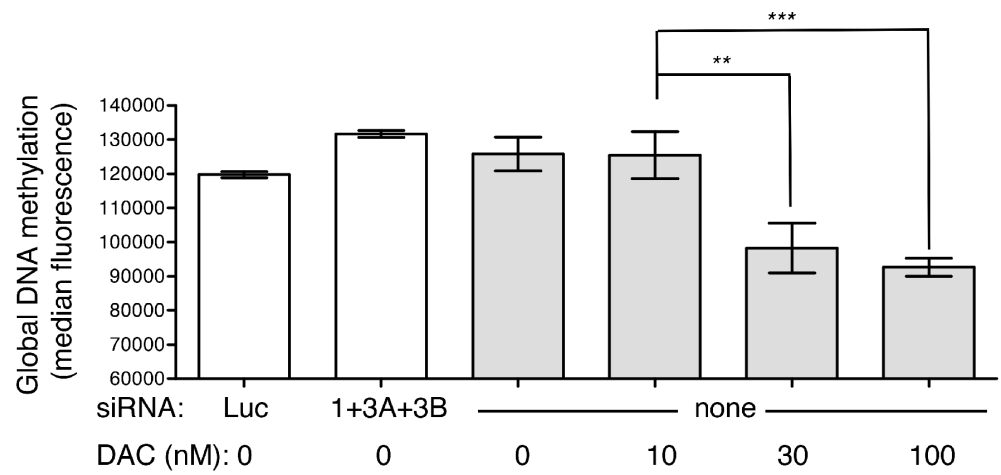

C

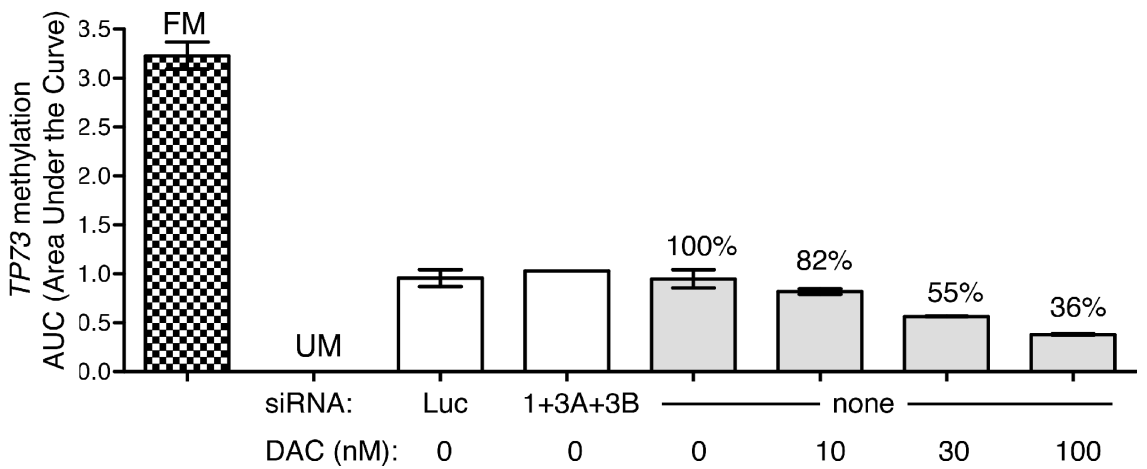

Figure 1: Impact of DNMT downregulation on global DNA methylation and TP73 promoter methylation. (a) Western blot of DNMT1, 3A and 3B in KG1 cells treated with the combination of siRNAs directed against DNMT1 (100 nM), DNMT3A (300 nM) and $D N M T 3 B(300 \mathrm{nM})$, compared to siRNA directed against luciferase (Luc, at $700 \mathrm{nM})$ ), and to a dose range of DAC (10,30 and 100 $\mathrm{nM})$. Actin protein was revealed on the same membranes and used to normalize for loading variations. The bands shown in the first quadrants (siRNA treated cells) have been cropped and come from the same gel (the full gels are accessible in Supplementary Figure S2). The relative percentages for each DNMT protein in response to the treatments are indicated (in \%) and are the mean values of two independent experiments. The image shown is representative of one of these two. (b) The same cells were analyzed for total DNA methylation by flow cytometry (white bars cells treated with siRNA, gray bars cells treated with DAC). $P$-value: $* * \leq 0.01$ and $* * * \leq 0.001$. (c) $T P 73$ promoter region methylation was assessed by MS-HRM analysis. The areas under the curves are reported for siRNA treated cells (white bars) and DAC-treated cells (gray bars). FM, fully methylated DNA control, UM, unmethylated DNA control. 
a
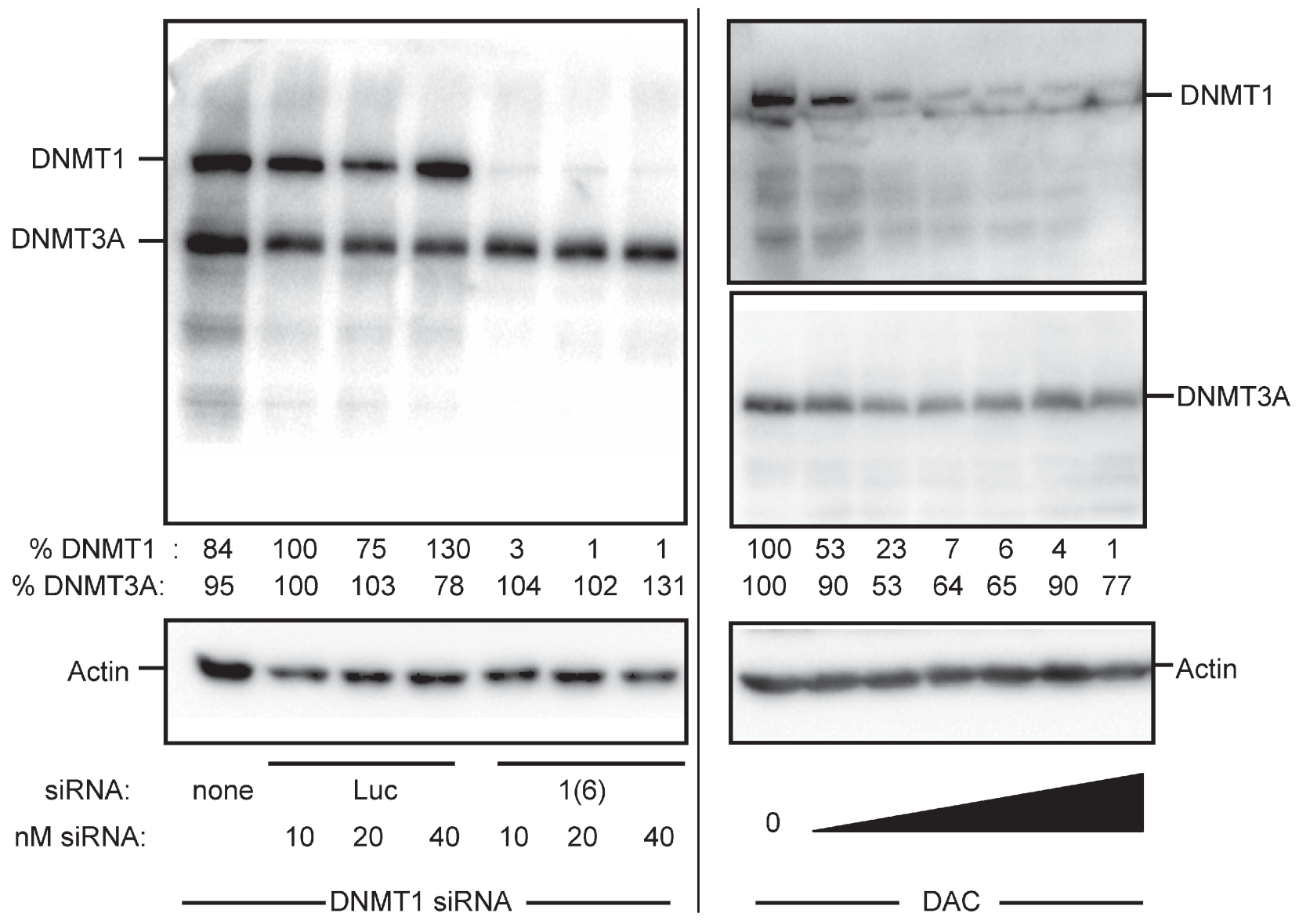

0

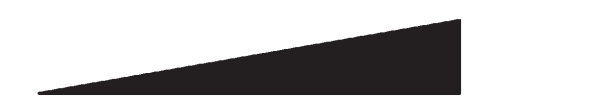

b

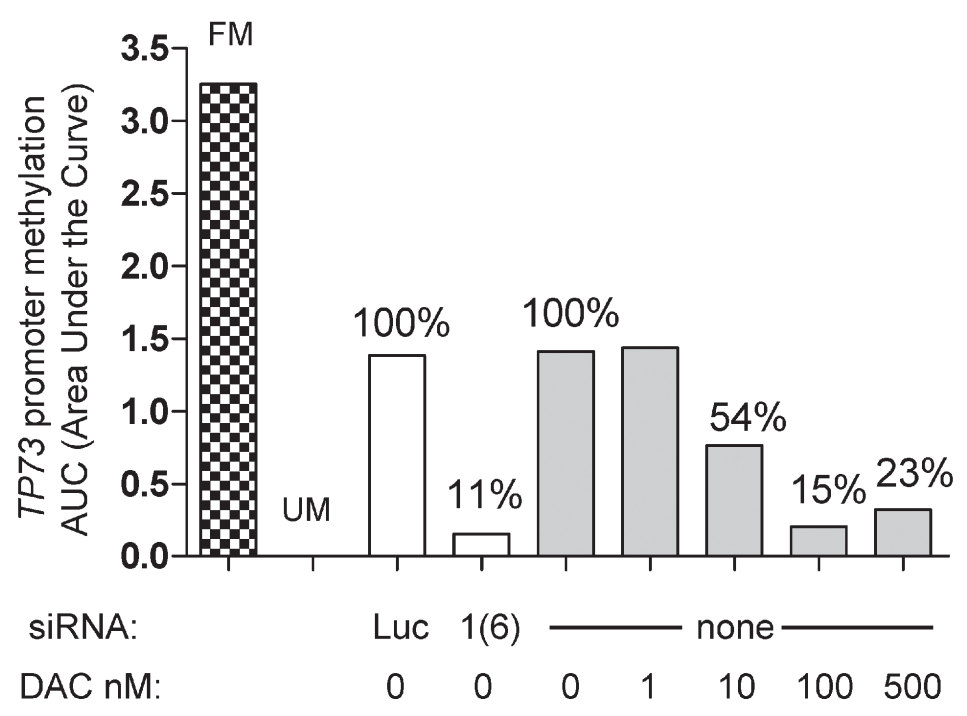

Figure 2: Impact of extensive DNMT1 depletion in HCT116 cells on TP73 promoter methylation. HCT116 human colon cancer cells have been transfected every two days for four days with the same DNMT1 siRNA (1(6)) used in KG1 cells, or exposed for 72 hours to a dose range of DAC $(0,0.001,0.01,0.03,0.1,1,10 \mu \mathrm{M})$. (a) Two days after the first transfection, total proteins were extracted and subjected to Western blotting with DNMT1 and DNMT3A antibodies. Actin was used as loading control. The percentages of residual DNMT protein levels are indicated relative to the corresponding untreated controls normalized to 100\% (b) Four days post-transfection DNA was extracted and subjected to MS-HRM analysis to evaluate the impact of DNMT1 depletion on TP73 promoter methylation. In parallel with the siRNA treatment, HCT116 cells were exposed to a dose range of DAC for 72 hours (fresh DAC was added every day). FM, fully methylated DNA control, UM, unmethylated DNA control. 

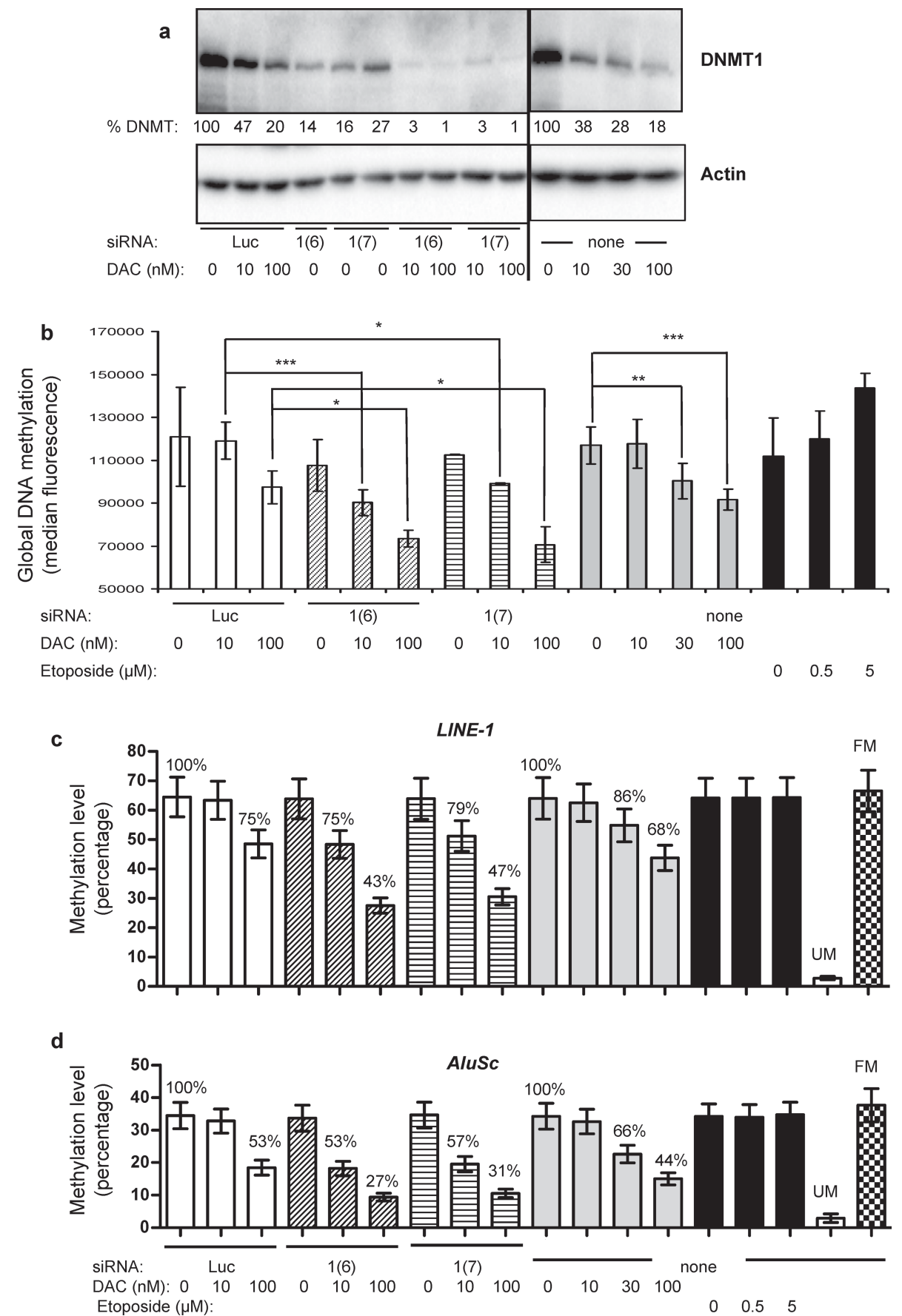

Figure 3: Effect of combining DNMT1 siRNA and DAC on global DNA methylation and on the methylation of LINE-1 and $A \boldsymbol{l u S C}$ repeated sequences. (a) DNMT1 Western blot performed on KG1 cells exposed to combination of siRNA ( $L u c, D N M T 1(6)$ or DNMTI(7)) and two doses of DAC (10 and $100 \mathrm{nM}$ ) (left), compared to DAC-treated cells at 10,30 or $100 \mathrm{nM}$ (right). The full gel images are accessible in Supplementary Figure S6. The percentages of DNMT1 protein level (\% DNMT1) normalized to 100\% for their respective control (siLuc for electroporated cells and non treated for DAC treatment) are indicated. The image shown is representative of two independent experiments, except for the siRNA 1(7) that was tested in duplicates in this experiment (b) $72 \mathrm{~h}$ post-treatment, cells were collected and total DNA methylation was measured by flow cytometry for cells treated with siRNA Luc $(100 \mathrm{nM})$ alone or combined with 10 or $100 \mathrm{nM}$ DAC (white bars), siRNA $D N M T 1(6)(100 \mathrm{nM}$ ) alone or combined with 10 or $100 \mathrm{nM}$ DAC (hatched bars); siRNA $\operatorname{DNMTI}(7)(100 \mathrm{nM}$ ) alone or combined with 10 or $100 \mathrm{nM}$ DAC (striped bars); DAC alone at 10, 30 and $100 \mathrm{nM}$ (gray bars) or etoposide at 0.5 or $5 \mu \mathrm{M}$ (black bars). $P$ value: $* \leq 0.05, * * \leq 0.01$ and $* * * \leq 0.001$. (c- - d) KG1 cells treated for 72 hours with various combinations of DNMT1 siRNA (1(6) and 1(7)) and DAC were analyzed by bisulfite conversion followed by pyrosequencing for methylation changes in LINE-1 (c) and AluSc (d). Cells were treated also with increasing concentration of etoposide. The mean methylation level of all CpG present in the sequenced DNA and the standard error are represented. The percentage of demethylation (normalized to $100 \%$ for the controls, i.e. luciferase siRNA and untreated cells) are also indicated. FM, fully methylated DNA control, and UM, unmethylated DNA control. 
role of DAC-induced DNA damage in the demethylation process [28], we explored the effect on DNA methylation of etoposide, a well-know DNA topoisomerase II poison leading to DNA breaks. Unlike DAC this compound was unable to induce any global DNA demethylation (Figure $3 b$ ). We then addressed whether this combination of treatments was able to demethylate specific TSG promoters and induce their re-expression.

\section{Combining DNMT1 siRNA and DAC induces TP73 promoter demethylation associated with gene re-expression}

As previously reported [29, 30], the promoter regions of three TSGs, namely TP73, CDH1 and $C D K N 2 B$, are hypermethylated in KG1 cells (Figure 4 and Supplementary Figure S4). As expected, a dose range of DAC induced, after $72 \mathrm{~h}$ of daily treatment, a significant demethylation of all three genes, with $30 \mathrm{nM}$ as the first significantly effective dose and achieving a stronger demethylation at $100 \mathrm{nM}$ (Figure 4). In agreement with our observations on global DNA methylation, etoposide was unable to induce demethylation of the three promoters (Figure 4). Interestingly, the combined treatment of DNMT1 siRNA with the demethylation-inactive dose of 10 $\mathrm{nM}$ DAC induced a strong and significant demethylation of all three TSGs, equivalent to higher doses of DAC alone (Figure 4). These results were obtained with both siRNAs against DNMT1. To further confirm these observations, promoter DNA methylation was analyzed by bisulfite conversion followed by pyrosequencing (Supplementary Figure S7), confirming the data obtained by MS-HRM. Noteworthy, in the case of TP73, pyrosequencing did not only confirm the demethylation activities seen by MSHRM, but also assessed the impact of the combination on the methylation of the second promoter (P2) described for this gene (Supplementary Figure S8). Thus an extensive depletion of DNMT1 in KG1 cells, obtained by combining siRNA and DAC at low dose, induced global DNA demethylation and specific TSG promoter demethylation, among them TP73. This prompted us to study whether this demethylation affected TP73 mRNA expression. DAC alone restored TP73 expression in a dose-dependent manner $72 \mathrm{~h}$ after treatment as measured by qRT-PCR (Figure 4d). DNMT1 siRNAs alone showed no effect, while when combined with $10 \mathrm{nM}$ DAC, a modest but significant induction of TP73 mRNA was measured (Figure 4d). Interestingly, even if the extent of DNA demethylation was equivalent, the extent of re-expression was lower (two-fold change) than with DAC alone at higher concentration (eight-fold change), implying that another mechanism induced by DAC is involved. Unexpectedly, when combined with $100 \mathrm{nM}$ DAC, the siRNAs (luc and DNMT1) suppressed partially TP73 gene re-expression induced by DAC alone at the same concentration (Figure 4d). Finally, etoposide induced TP73 mRNA expression without having any impact on the methylation of the promoter, suggesting that DNA damage can induce TP73 mRNA expression. Due to their very low expression level, $C D H 1$ and $C D K N 2 B$ re-expression were not followed (data not shown).

\section{SiRNA-mediated DNMT1 depletion reverts the $\gamma H 2 A X$ phosphorylation and G2/M blockade induced by $100 \mathrm{nM}$ DAC}

Next we investigated the role of DNA damage induced by DAC at high doses, since etoposide, a DNA damaging agent, induced TP73 re-expression and another mechanism than DNA demethylation seemed to be involved in TP73 re-expression induced by DAC. The phosphorylation of $\gamma \mathrm{H} 2 \mathrm{AX}$, a histone variant induced by DNA damage, was analyzed upon treatment of KG1 cells (Figure 5a). DAC alone induced a dosedependent increase in the percentage of cells expressing phosphorylated $\gamma \mathrm{H} 2 \mathrm{AX}$ with $20 \%$ positive cells at 100 $\mathrm{nM}$. Etoposide was used as positive control (57\% positive cells at $5 \mu \mathrm{M})$, as it induces DNA double-stranded breaks through the formation of topoisomerase II-DNA covalent complexes, similar to the DNMT-DNA adducts formed upon exposure to DAC $[13,31,32]$. Both DNMT1 siRNAs did not induce any significant phospho- $\gamma \mathrm{H} 2 \mathrm{AX}$ signal (Figure 5a). Interestingly, the combination of DNMT1 siRNAs and $100 \mathrm{nM}$ DAC strongly reduced the percentage of $\gamma \mathrm{H} 2 \mathrm{AX}$ phosphorylated positive cells (from $25 \%$ to less than $5 \%$ ). Similarly, previously published data showed that knocking down topoisomerase II is associated with a reduced level of DNA damage induced by doxorubicin and etoposide $[33,34]$. This is the result of a reduced formation of covalent adducts involving topoisomerase II, DNA, and the aforementioned topoisomerase II inhibitors. We then explored the consequences of the modulation of $\gamma \mathrm{H} 2 \mathrm{AX}$ phosphorylation on the cell cycle. In agreement with previous reports [16-18, 35], DAC induced a G2/M arrest in response to the activation of the $\mathrm{G} 2 / \mathrm{M}$ checkpoint triggered by DNA damage (Figure 5b). Clearly, the DNMT1 siRNAs reverted the G2/M blockade induced by $100 \mathrm{nM}$ DAC (Figure 5b, and Supplementary Figure $\mathrm{S} 9$ for a focus on $\mathrm{G} 0 / \mathrm{G} 1$ and G2/M phases). Finally, the impact on KG1 cell growth was explored. Since DAC is known to induce a delayed effect on cell proliferation [36], the cell viability was measured seven days after the first treatment (Figure 5c). As expected, DAC induced a dose-dependent loss of cell viability of $50 \%$ and $90 \%$ at $30 \mathrm{nM}$ and $100 \mathrm{nM}$, respectively. Although clearly reversing $\gamma \mathrm{H} 2 \mathrm{AX}$ phosphorylation and G2/M blockade, siRNA-mediated downregulation of DNMT1 did not protect the cells from the loss of viability measured seven days after exposure to repeated DAC treatments (Figure 5c). 

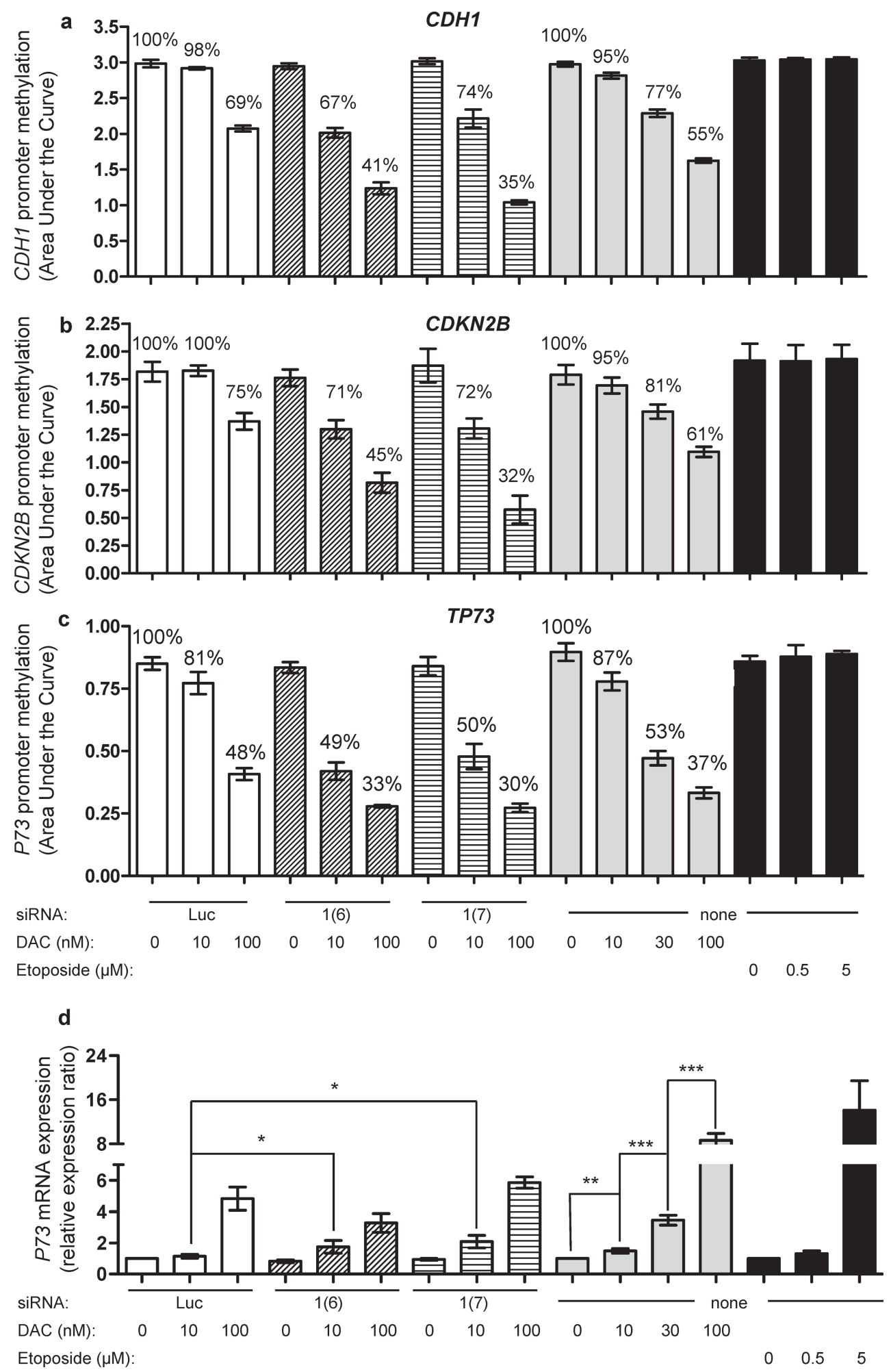

Figure 4: Impact of combining DNMT1 siRNA with DAC on promoter methylation of CDH1 and CDKN2B, and promoter methylation and expression of TP73. $C D H 1$. (a), $C D K N 2 B$ (b) and $T P 73$ (c) methylation was measured by MS-HRM $72 \mathrm{~h}$ after treating the cells with $D N M T$ siRNA $L u c(100 \mathrm{nM}$, white bars), siRNA $D N M T 1(6)$ at $100 \mathrm{nM}$ (hatched bars), siRNA $D N M T 1(7)$ at $100 \mathrm{nM}$ (stripped bars) and in combination with DAC (10 and $100 \mathrm{nM}$ ) (left), compared to DAC alone at 10,30 and $100 \mathrm{nM}$ (gray bars) or etoposide at 0.5 and $5 \mu \mathrm{M}$ (black bars) (right). The mean percentage values of methylation, relative to the respective controls are indicated. (d) qRT-PCR analysis of TP73 mRNA expression of the above treated cells. The expression ratio of the controls was normalized to 1, i.e., luciferase siRNA (for electroporated cells), water (the solvent of DAC) and DMSO (the solvent of etoposide), respectively. $P$ value: $* \leq 0.05, * * \leq 0.01$ and $* * * \leq 0.001$. 

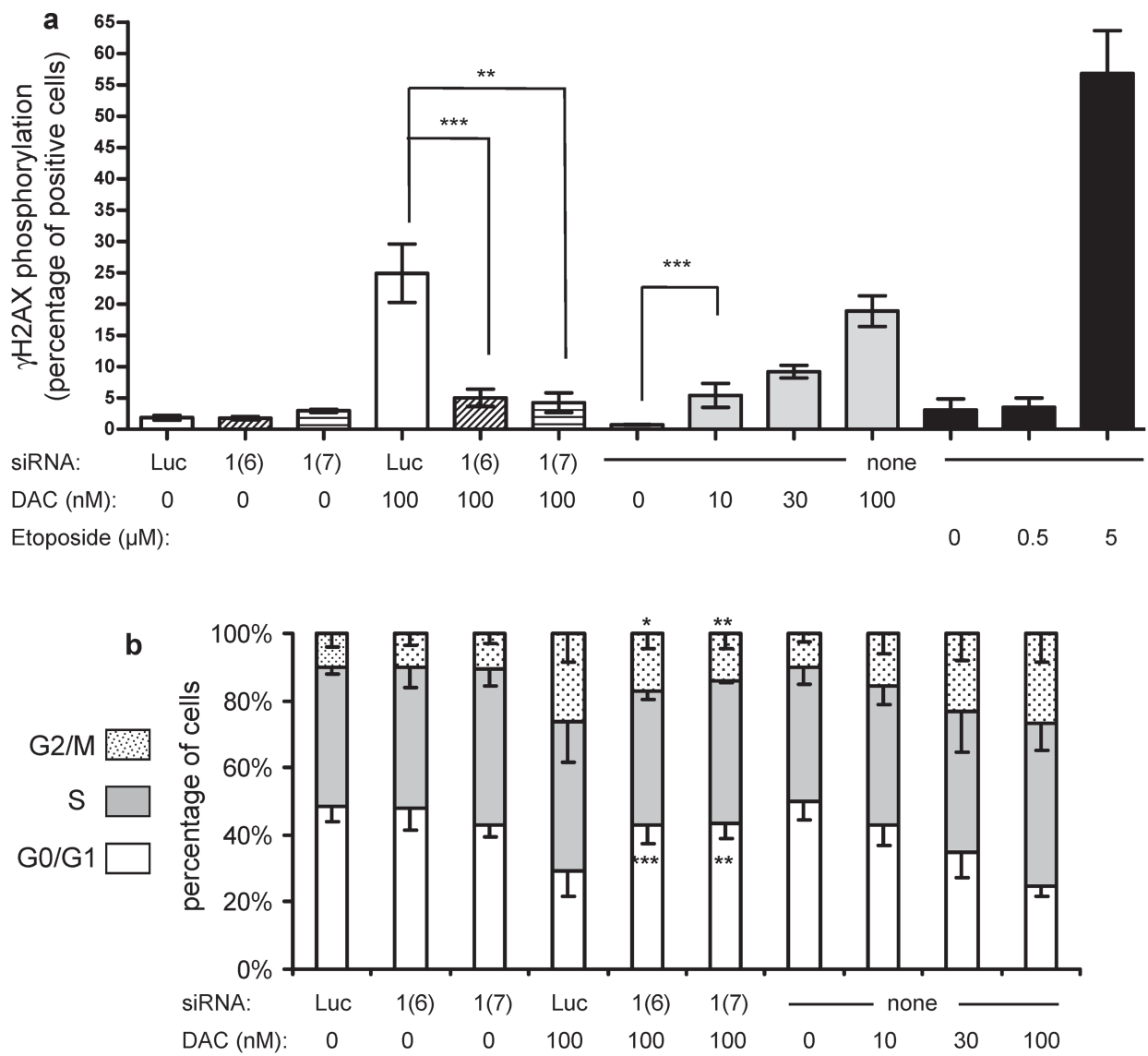

C

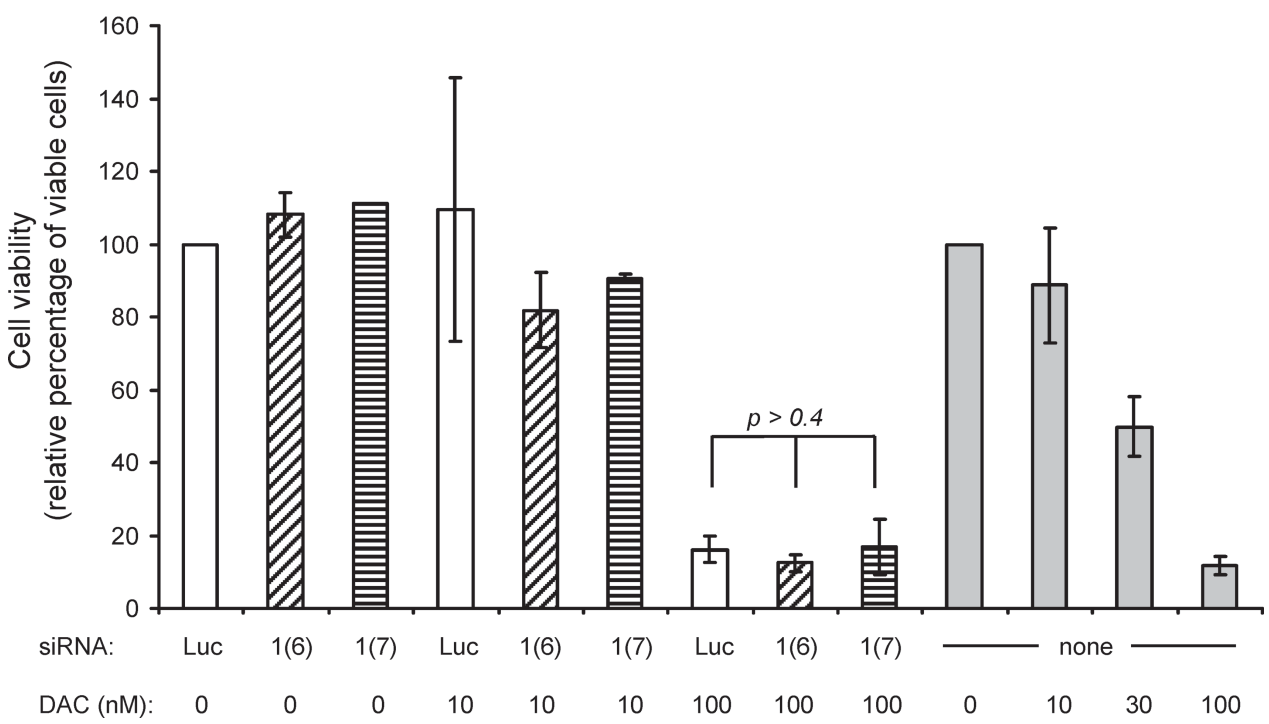

Figure 5: $\gamma \mathrm{H} 2 \mathrm{AX}$ phosphorylation labeling, cell cycle and cell viability analysis $72 \mathrm{~h}$ after treatment. (a) The percentages of positive cells for $\gamma \mathrm{H} 2 \mathrm{AX}$ phosphorylation are reported for siRNA at $100 \mathrm{nM}$ (siLuc, white bars, siDNMTl(6) hatched bars and siDNMTI(7) stripped bars) alone or in the presence of $100 \mathrm{nM} \mathrm{DAC}$; for DAC alone at 10,30 and $100 \mathrm{nM}$ (gray bars) or for etoposide at 0.5 and $5 \mu \mathrm{M}$ (black bars). $P$-value: $* * \leq 0.01$ and $* * * 0.001$. (b) The cell cycle repartition, indicated as percentages of cells in each phase (G0/G1 lower bars, S middle bars, G2/M upper bars), is shown for the various treatments applied to the cells. The stars on the histogram refer to the $p$-values calculated for both $\mathrm{G} 0 / \mathrm{G} 1$ and G2/M compartments in KG1 cells treated with $100 \mathrm{nM}$ DAC combined with either DNMT1 siRNA1(6) and 1(7) versus the cells exposed to $100 \mathrm{nM}$ DAC combined with the control siRNA ( $L u c)$. (c) After $\gamma \mathrm{H} 2 \mathrm{AX}$ phosphorylation measurement, cells from the same batch were seeded for another 4 days and cell viability assessed. The percentage of viable cells is indicated relative to their respective controls (siLuc and $0 \mathrm{nM} \mathrm{DAC}$ ) set to $100 \%$ viable cells. White bars: $100 \mathrm{nM}$ si $L u c$; hatched bars: 100 nM siDNMT1(6); stripped bars: $100 \mathrm{nM} D N M T 1(7)$; gray bars: DAC at 10, 30 and $100 \mathrm{nM}$. 


\section{A genome wide analysis of DNA methylation changes at $450000 \mathrm{CpGs}$ induced by the combination of DNMT1 siRNA and DAC}

Next, the effect of the combination of the siRNA against DNMT1 with a low dose of DAC was explored at the genome-wide level using the Illumina $450 \mathrm{~K} \mathrm{CpG}$ BeadChips. Unsupervised clustering analysis confirmed that cells treated with the high concentration of $100 \mathrm{nM}$ DAC sustain similar methylation changes than those treated with the low dose of DAC $(10 \mathrm{nM})$ combined with the DNMT1 siRNA (group 1 in Figure 6a). Non-treated cells, cells treated with low concentration of DAC and cells transfected with DNMT1 siRNA alone clustered together in group 2 (Figure 6a). Since it is known that DNA methylation of promoters has a direct role in genes transcription, we focused our analysis on the genes for which the modulated $\mathrm{CpG}$ are located within, or in a close vicinity, of their corresponding transcription start site (TSS). We identified 689 hypomethylated genes in group 1, including $C D K N 2 B$, in agreement with our MS-HRM and pyrosequencing data. Most surprisingly, we observed also that 1254 genes were hypermethylated in this same group 1 (Supplementary Table S2 and S3 for the lists of hypo- and hypermethylated genes, respectively). Next, we analyzed the pathways that were mostly affected by hypomethylation changes in group 1, using the Ingenuity Analysis Pathway ${ }^{\circledR}\left(\right.$ IPA $\left.^{\circledR}\right)$ tool. The most significantly affected pathways (i.e., with the lower $p$-values, $-\log (p$ value) $>2$ ) concerned major cell signaling pathways that share several common factors with NF-kB network (Figure 6b, genes in bold in the table). This observation suggested that main apoptosis/proliferation functions are affected by hypomethylation following DNMT1 strong depletion (100 nM DAC or $10 \mathrm{nM}$ DAC combined with siDNMT1).

\section{DISCUSSION}

Our data show that all three DNMT1/3A/3B are expressed in KG1 cells, with DNMT1 and 3B being predominant. This is in agreement with previous data on CD34 ${ }^{+}$leukemia cell lines, such as KG1, showing high expression of DNMT3B [37]. Surprisingly, partial DNMT downregulation by siRNA in KG1 cells (60 to $90 \%$ ) did not induce any global or specific DNA demethylation, in contrast to what has been observed in HCT116 cells, where we could achieve a DNMT1 depletion $>95 \%$. To explain these apparent discrepancies, we suggest that KG1 cells express high levels of the three DNMT1/3A/3B, and particularly of DNMT1, which exceeds the minimum amount required to maintain $\mathrm{CpG}$ methylation (Figure 7). This minimal amount defines the threshold, below which DNA demethylation is observed (Figure 7a). First, while in $10 \mathrm{nM}$ DAC co-treated cells the DNMT1 that is not depleted can be trapped on the DNA by the incorporated
DAC (Figure 7b), in the siRNA treated cells all residual DNMT1 is mobilized to ensure DNA methylation (Figure 7b). This explains why the siDNMT1 are unable to demethylate DNA in KG1 cells. In agreement with this hypothesis Patel and coll. showed that in DAC treated cells the formation of cytosine adducts are more critical for DNA demethylation than the residual level of DNMT1 [38]. Second, in the case of DNMT1 siRNA combined with a low dose of DAC, the free available pool of protein drops below the minimally required amount and induces DNA demethylaton, but with reduced DNA damage (Figure 7d) compared with $100 \mathrm{nM}$ DAC (Figure 7c). This combined treatment allows then to reveal the passive demethylation component of DAC, in contrast to the active demethylation involving the formation of DNA damage. Nonetheless, we cannot rule out the possibility that the low dose of DAC used $(10 \mathrm{nM})$ in combination with $D N M T 1$ siRNA could participate in a more active manner than just lowering the level of DNMT1 available for DNA methylation. In conclusion, this study reveals an essential role of DNMT1 in maintaining DNA hypermethylation in KG1 cells, in contrast to DNMT3B, which is abundant in KG1. Regarding DNMT3A, its expression is already low in KG1 cells. It is also possible that DNMT3A and/or DNMT3B play other roles in addition to DNA methylation management, since Hagemann and coll. recently reported that DNMT3B depletion in human colon cancer cells induced cell growth arrest and apoptosis without changes in their DNA methylation pattern [39].

Concerning the role of DNA damage in DNA demethylation, it has been suggested that formation of the suicide complex between incorporated DAC and DNMT participates to DNA demethylation through a DNA repair mechanism, a process referred to active demethylation [28]. Here we clearly separated DNA damage formation and DNA demethylation by combining DNMT1 siRNA and low doses of DAC, since this combination induced DNA demethylation with lower DNA damage compared to DAC alone at $30 \mathrm{nM}$ or $100 \mathrm{nM}$. Interestingly, two recent studies showed that depleting either DNMT1 or DNMT3B in cancer cells protects them from gene misregulation and cell cycle arrest induced by a DAC treatment, hence supporting our present findings $[14,15]$. Accordingly, the suppressive effect of DNMT1 siRNA on DAC-mediated TP73 mRNA induction that we observed could well be explained by a significant reduction of DNA damage, through lowering the DNMT1-DNA adduct formation that would participate, at least in part, in the gene re-expression.

Another main conclusion is that the antiproliferative effect of DAC does not seem to be associated with its ability to induce DNA breaks. Indeed, the DNMT1 siRNAs combined with low doses of DAC, which induced the same DNA demethylation as high DAC doses but with lower DNA damage, had the same cell viability inhibition at 7 days as DAC at high doses. This result suggests that 
Height

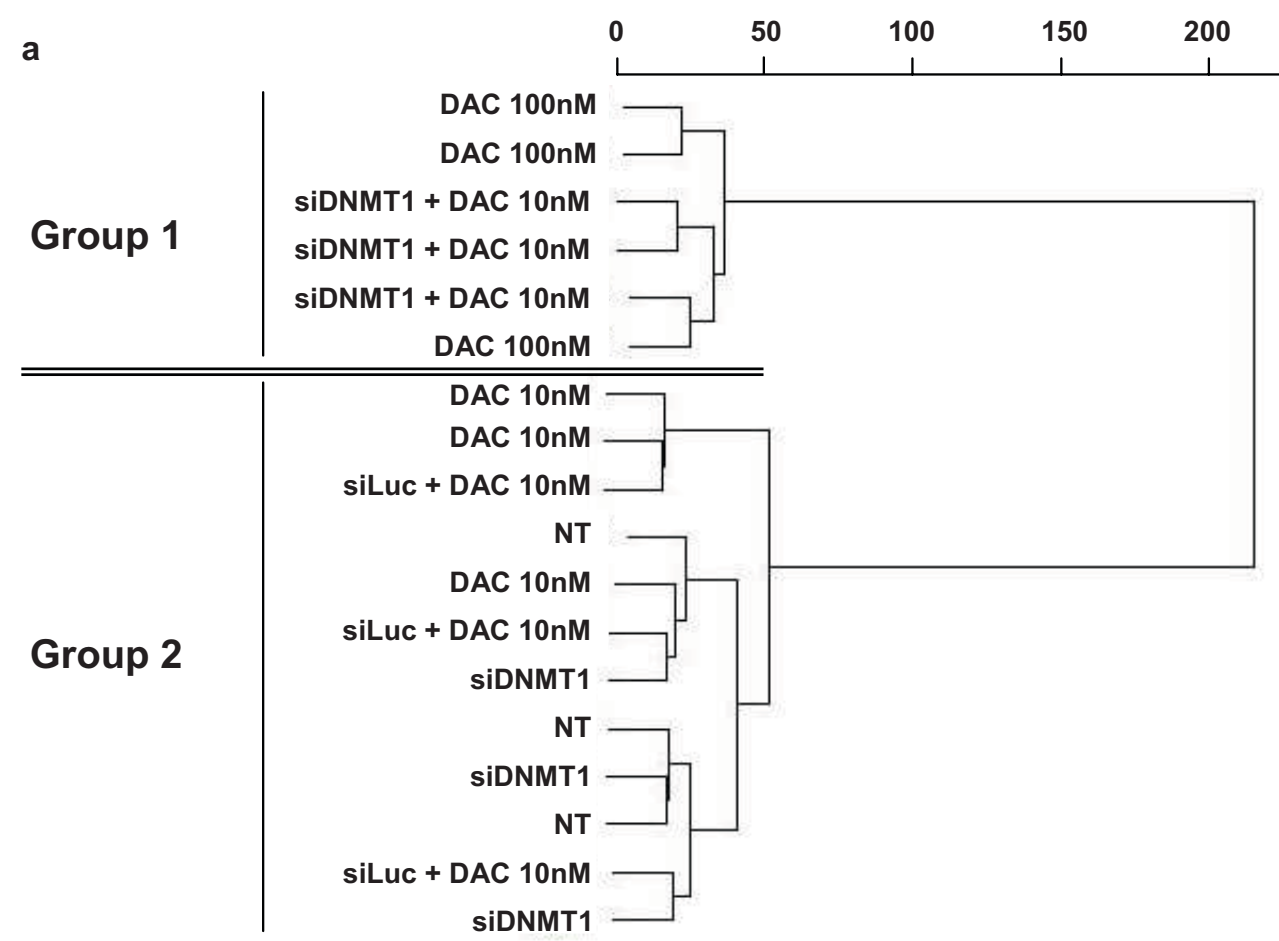

b Enriched pathways for hypomethylated genes in group1 vs group2

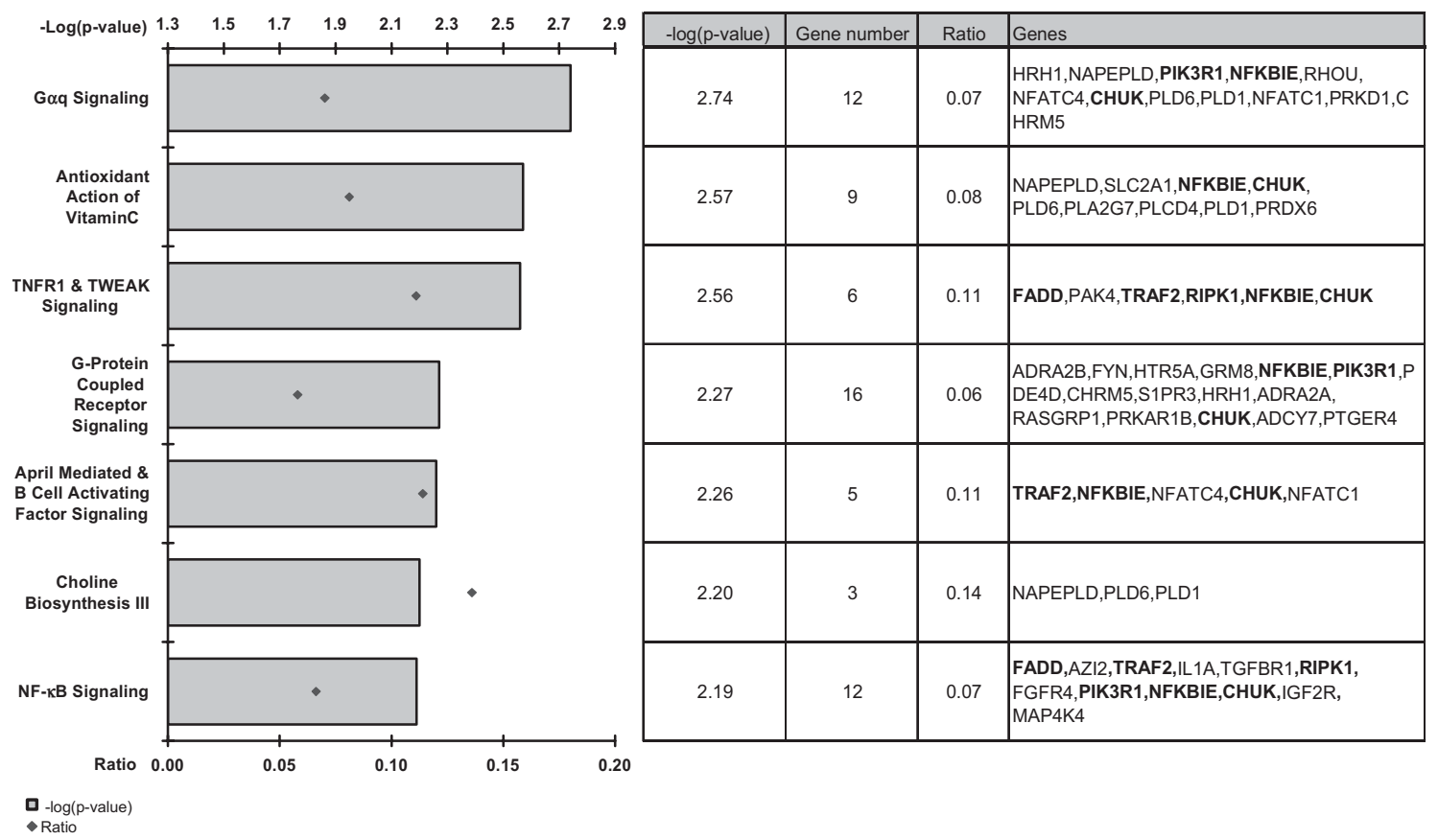

Figure 6: Genome-wide methylation analysis. The genomic DNA extracted from treated KG1 cells was analyzed on an Illumina $450 \mathrm{~K} \mathrm{CpG} \mathrm{microarray.} \mathrm{(a)} \mathrm{The} \mathrm{clustering} \mathrm{analysis} \mathrm{shows} \mathrm{two} \mathrm{groups:} \mathrm{group} 1$ corresponding to cells treated by $100 \mathrm{nM}$ DAC or the combination of siDNMT1(6) and $10 \mathrm{nM} \mathrm{DAC}$; and group 2, corresponding to non-treated cells (NT), cells treated with $10 \mathrm{nM}$ DAC, the combination of siLuc and $10 \mathrm{nM}$ DAC or siDNMT1 alone. Biological triplicates have been performed for each condition. (b) IPA ${ }^{\circledR}$ pathways analysis of hypomethylated genes enriched in group $1 \mathrm{vs}$. group 2. Bar plots, on the left, show the canonical pathways the most significantly represented in group 1 (threshold $p$-value $<0.01$ ) and the ratio values corresponding to the proportion of deregulated genes among all genes found in each pathway. The table on the right gives a detailed view of the genes hypomethylated in each pathway. The genes involved in the NF-kB pathway are in bold. 


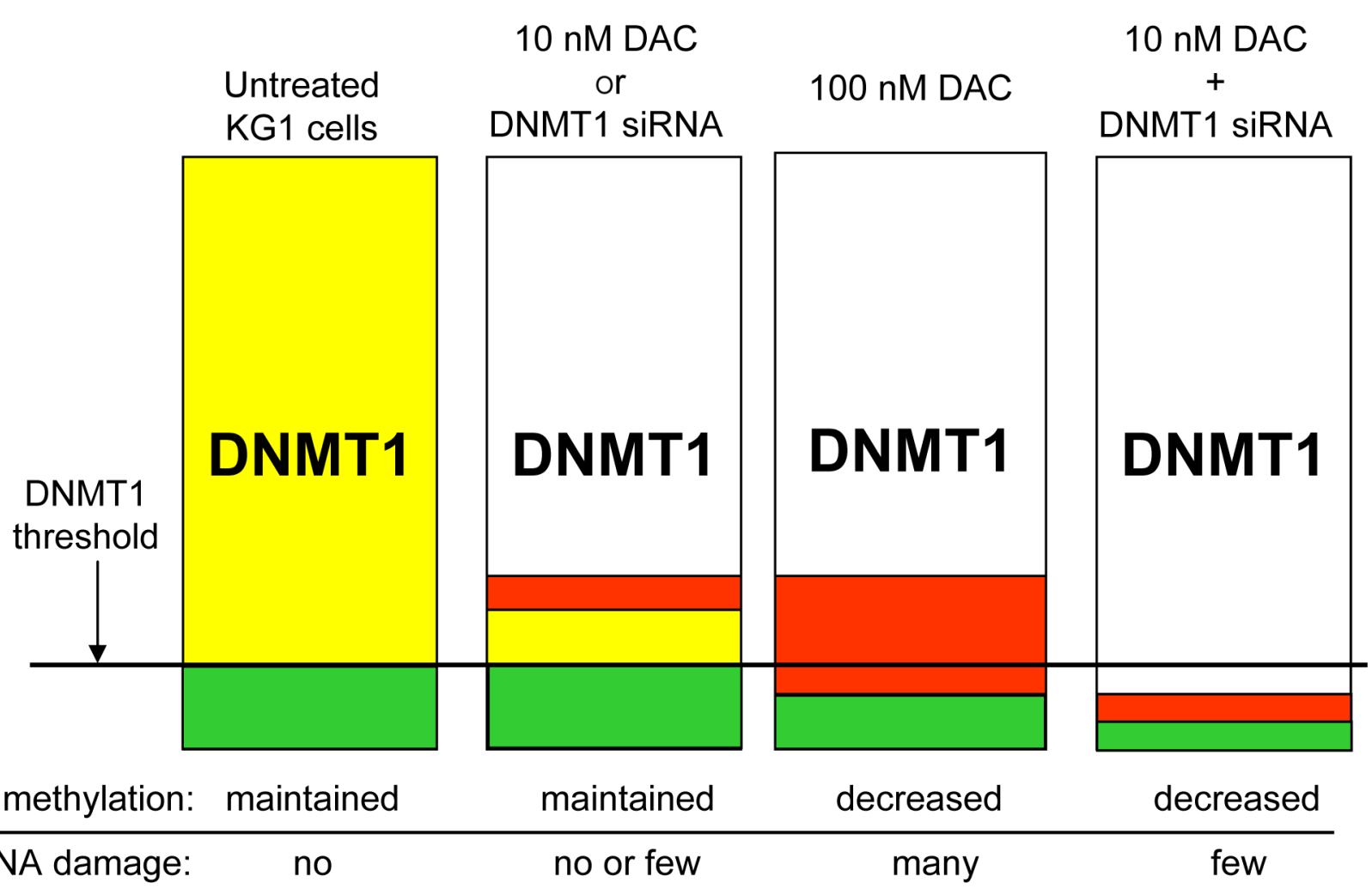

Figure 7: Schematic representation of the DNMT1 threshold hypothesis for DNA methylation maintenance. (a) In KG1 cells the physiological level of DNMT1 is largely above the minimum amount to ensure proper DNA methylation propagation, defining a reservoir of protein (yellow). (b) The partial loss of DNMT1, either by a low dose of DAC (10 nM) or a siRNA specific to DNMT1, reduces the DNMT1 content, but the remaining free pool (green + yellow) is sufficient to maintain the CpG methylation, even though a small proportion of detected DNMT1 can be trapped by the DAC incorporated into DNA (red), leading to few DNA breaks, which is not the case for the siRNA. (c) A higher dose of DAC $(100 \mathrm{nM})$ strongly lowers the free DNMT1 pool below the critical threshold, triggering global and specific DNA demethylation. At the same time, DNMT1-DAC adducts formed on DNA translate into DNA breaks visualized by $\gamma \mathrm{H} 2 \mathrm{AX}$ phosphorylation. (d) Depletion of the DNMT1 pool, below the threshold, can also be achieved by combining a low dose of DAC with a siRNA directed against DNMT1. Similar to a high dose of DAC (i.e. $100 \mathrm{nM}$ ) this combination induces a global and gene-specific DNA demethylation, but little DNA damage, since less DAC and also less DNMT1, downregulated by the siRNA, are present to form the DNMT-DNA adducts and consequent DNA damage.

Yellow box: Reservoir of DNMT1 not required to maintain DNA methylation Green box: Pool of DNMT1 required to ensure DNA methylation maintenance Red box: Pool of DNMT1 that can be trapped on DNA by DAC and be converted into DNA damage DNMT1 threshold = defines the minimal pool of DNMT1 required for DNA methylation maintenance

the induced DNA demethylation plays an important role in affecting cell growth, possibly by the re-expression of TSGs, ultimately leading to cell cycle arrest and cell death. We thus succeeded in turning the initial drawback of a partial DNMT1 depletion by siRNA in KG1 cells into an advantage by combining this approach with low dose of DAC, giving insights into the mechanism of action of DAC and one of its main targets, DNMT1.

To further compare the effect of the downregulation of DNMT1 by DAC or by the combination of siRNA and non-demethylating doses of DAC, we performed a microarray analysis to explore the methylation changes in the genome. Again the two treatments that strongly depleted DNMT1 clustered together compared to the controls, $10 \mathrm{nM}$ DAC or DNMT1 siRNA alone. Interestingly, in parallel to a general hypomethylating activity, we observed promoter hypermethylation of certain genes. Nevertheless, we cannot exclude that different cell populations are present in the bulk and behave differently. The analysis of the pathways that are hypomethylated in the treated KG1 cells compared to the non-treated converges on genes related to several cell signaling pathways as targets of the combination of DAC and DNMT1 siRNA (Figure 6). The NF-kB network (i.e. FADD, TRAF2, RIPK1, PIK3R1, NFKBIE and CHUK, in bold in Figure 6b) is clearly affected and may be involved in the antiproliferative activity of this combination. 
Finally, two recent articles report the successful TSG induction in cancer cells by combining DAC with the inhibition of two other epigenetic modifiers, HDAC and LSD1 [40, 41]. These data combined with our present results support the rationale to test, in leukemia models, the combined treatment of DNMT1 selective inhibitors with already approved "epidrugs", such as HDAC inhibitors, or preclinically investigated molecules such as LSD1 inhibitors. Importantly, our data suggest that combining low doses of DAC with a DNMT1 selective inhibitor could achieve an efficient TSGs hypomethylation associated with a reduced impact on DNA damage and potentially reduce the side effects observed with high doses of DAC.

\section{METHODS}

\section{Cell lines and reagents}

KG1, HL60, Karpas299 and HCT116 cell lines were obtained from the ATCC repository (Manassas, VA, USA), and cultivated in RPMI1640 medium (BE12-115F, Lonza, Basel, Switzerland) complemented with $10 \%$ fetal calf serum (Gibco by Life Technologies, Cergy Pontoise, France), and under $5 \% \mathrm{CO}_{2}$. 5-Aza-2'-deoxycytidine (DAC) and etoposide were obtained from Sigma Aldrich (SaintQuentin Fallavier, France), and prepared as $10^{-2} \mathrm{M}$ aliquots in $\mathrm{H}_{2} \mathrm{O}$ and DMSO respectively, stored at $-20^{\circ} \mathrm{C}$ and used as dilutions freshly prepared in culture medium. The siRNAs used to target DNMTs and luciferase were purchased from
Qiagen (Courtaboeuf, France) and Fisher Scientific (Illkirch, France) respectively and stored at $-80^{\circ} \mathrm{C}$ before use.

\section{siRNA delivery}

In the case of KG1, the 4D-Nucleofector ${ }^{\mathrm{TM}}$ System (Lonza) was used to vector one or several siRNAs. In a typical experiment, $8 \times 10^{6}$ actively growing KG1 cells were transfected in $100 \mu \mathrm{L}$ SF solution with $100 \mathrm{nM}$ (DNMT1) or $300 \mathrm{nM}$ (DNMT3A or $3 B$ ) siRNA according to the manufacturer's instructions. Corresponding concentrations of luciferase siRNA were used as negative controls. Immediately after electroporation cells were collected in $5 \mathrm{~mL}$ fresh medium and incubated for the indicated time periods. The GFP-expressing vector pmaxGFP from Lonza was used to assess the transfection efficiency by flow cytometry $24 \mathrm{~h}$ posttreatment. Usually 70 to $80 \%$ cells expressed GFP. For HCT116, Lipofectamine ${ }^{\circledR}$ RNAiMAX Transfection Reagent from Invitrogen (by Life Technologies) was used to deliver DNMTI or luciferase siRNA to the cells. Briefly, a premix of $10 \mu \mathrm{L}$ siRNA (diluted in water to ensure final concentrations of 10, 20 and $40 \mathrm{nM}$ ) with $485 \mu \mathrm{L}$ OptiMEM (Invitrogen by Life Technologies) and $5 \mu \mathrm{L}$ transfection reagent was incubated for $25 \mathrm{~min}$. $250 \mu \mathrm{L}$ of this suspension was mixed with $1.5 \times 10^{5}$ cells and seeded in a 6 well plate. After the indicated period of time the cells were trypsinized for further analysis. Sequences of siRNAs used to target DNMTs:

\begin{tabular}{|c|c|c|c|}
\hline TARGET & sequence & Qiagen reference & Position (RefSeq) on mRNA variants (V) \\
\hline DNMT1(6) & $\begin{array}{l}\text { F: CAAUGAGACUGACAUCAAATT } \\
\text { R: UUUGAUGUCAGUCCUCAUUGGG }\end{array}$ & SI02663409 & $\begin{array}{l}\text { V1: } 3253-3273 \\
\text { V2: } 3205-3225\end{array}$ \\
\hline $\begin{array}{l}\operatorname{DNMT1}(7) \\
\operatorname{DNMT1}(7)\end{array}$ & $\begin{array}{l}\text { F: GGAAGUGAAUGGACGUCUATT } \\
\text { R: UAGACGUCCAUUCACUUCCCG }\end{array}$ & SI02663416 & V1+V2: 481-501 \\
\hline DNMT3A & $\begin{array}{l}\text { F: CAGUGGUGUGUGUUGAGAATT } \\
\text { R: UUCUCAACACACACCACUGAG }\end{array}$ & SI02665278 & $\begin{array}{l}\text { V1: } 1346-1364 \\
\text { V2: 559-577 } \\
\text { V3: 1275-1293 } \\
\text { V4: Non targeted }\end{array}$ \\
\hline DNMT3B & $\begin{array}{l}\text { F: GCUCUUACCUUACCAUCGATT } \\
\text { R: UCGAUGGUAAGGUAAGAGCTG }\end{array}$ & SI03068240 & $\begin{array}{l}\text { V1: } 807-827 \\
\text { V2: } 807-827 \\
\text { V3: } 807-827 \\
\text { V6: 786-806 } \\
\text { V7: 681-701 } \\
\text { V8: } 579-599\end{array}$ \\
\hline
\end{tabular}

As a control, we used the luciferase siRNA \#P0020990120 from Fisher Scientific herein abbreviated as $L u c$ or $L u c$ siRNA. Similarly, and for clarity reason, the other siRNAs directed at DNMT1, $3 A$ and $3 B$, are referred in the figures legends as 1 or 1(6), 1(7), $3 \mathrm{~A}$ and $3 \mathrm{~B}$ respectively.

\section{Quantitative Real-time PCR (qRT-PCR)}

The cDNA, obtained from $1 \mu \mathrm{g}$ total RNA by using the SuperScript ${ }^{\mathrm{TM}}$ II Reverse Transcriptase following the manufacturers instructions (Life Technologies) coupled to the random primer from Promega (Charbonnières- 
les-Bains, France), were used at 1/25 dilution to perform real-time PCR reactions with a SYBR ${ }^{\circledR}$ Green PCR Master Mix kit from Applied Biosystems (by Life Technologies), using $400 \mathrm{nM}$ of each forward (F) and reverse (R) primer obtained from Eurogentec (Angers, France). We used a CFX384 Touch ${ }^{\mathrm{TM}}$ Real-Time PCR Detection System from Biorad (Marnes-la-Coquette, France) to run the following PCR program: $95^{\circ} \mathrm{C} 10 \mathrm{~min}$ followed by 40 cycles of 15 sec at $95^{\circ} \mathrm{C}, 1 \mathrm{~min}$ at $65^{\circ} \mathrm{C}$ for elongation, ended with a fusion cycle to determine the $\mathrm{Tm}$ of each amplification product. The PCR data were analyzed with the CFX Manager v3.0 software from Biorad to generate the $\mathrm{Ct}$ values and relative expression ratios. The following quality controls were applied: amplification of a single product, no amplification in the NRT (No reverse transcription) condition, efficiency close to $100 \%$, and $\mathrm{R}^{2}$ above 0.98 . The $2^{-\Delta \Delta C t}$ method was used to generate the gene expression ratios, and the mean $\mathrm{Ct}$ values from three reference genes, i.e. PPIA, TBP, and YWHAZ were used to normalize for cDNA input variations [42].

\section{Sequences of real-time PCR primers}

\begin{tabular}{|l|l|l|}
\hline \multicolumn{1}{l}{ TARGET } & \multicolumn{1}{c}{ sequences } & Position (RefSeq) on mRNA and amplified variants (V) \\
\hline$T P 73$ & $\begin{array}{l}\text { F: GGACGTACTCCCCGCTCTTGA } \\
\text { R: TCCGCTTTCTTGTAAACAGGCATG }\end{array}$ & All 13 variants are theoretically amplified \\
\hline PPIA & $\begin{array}{l}\text { F: GAGCACTGGAGAGAAAGGATTTGGTT } \\
\text { R: CGTGTGAAGTCA-CCACCCTGACA }\end{array}$ & $200-289$ \\
\hline$T B P$ & $\begin{array}{l}\text { F: TTGACCTAAAGACCATTGCACTTCGT } \\
\text { R: TTACCG-CAGCAAACCGCTTG }\end{array}$ & $610-678(\mathrm{~V} 2)$ \\
\hline$Y W H A Z$ & $\begin{array}{l}\text { F: CCCTCAAACCTTGCTTCTAGGAGA } \\
\text { R: TCATATCGCTCAGCCTGCTCG }\end{array}$ & $168-214(\mathrm{~V} 4)$ \\
\hline
\end{tabular}

${ }^{\$}$ For clarity reason the nucleotide positions on each TP73 amplicon are not indicated.

\section{Western blots}

SDS-PAGE was performed to measure the relative expression of DNMT1, 3A and 3B according to the procedure described by UK Leammli [43]. Briefly, 48 $\mathrm{h}$ after siRNA transfection or DAC exposure, $20 \mu \mathrm{g}$ total protein were loaded onto $8 \%$ polyacrylamide gel, separated through electrophoresis, transferred onto PVDF membrane, and incubated with the following primary antibodies, at the indicated dilutions: mouse antipan-actin 1:40 000 (MAB1501, Millipore, USA), rabbit anti-DNMT1 1:10 000 (NB100-264, Novus Biologicals, Littleton, CO, USA), rabbit anti-DNMT3A 1/500 (3598, Active Motif, Carlsbad, CA, USA), goat anti-DNMT3B 1:100 (N-19, sc-10235, Santa Cruz Biotechnology, Dallas, TX, USA). These antibodies were revealed with secondary HRP-coupled antibodies from Sigma Aldrich. All the incubation steps were performed in the following buffer: $200 \mathrm{mM} \mathrm{NaCl}, 20 \mathrm{mM}$ TrisHCl pH7.6, 0.1\% Tween 20. The Immobilon Western Chemiluminescent HRP Substrate from Merck Millipore (Darmstadt, Germany) was used to reveal the protein luminescent signals acquired on a ChemiDoc ${ }^{\mathrm{TM}}$ MP gel imaging system from Biorad and subsequently quantified with the Image Lab v4.0.1 software from Biorad. The signals from actin were used to normalize the protein loading variations. The relative expression values for each DNMT are represented by percentages obtained by the following formula: DNMT signal intensity value divided by the corresponding intensity for the actin giving a ratio normalized to $100 \%$ for each control sample.

\section{Total 5-methylcytosine labelling and FACS analysis}

The analysis of the total 5-methylcytosine $(5 \mathrm{mC})$ content in cells was performed according to the method described in Desjobert et al. [44]. Briefly, the cells were fixed with $4 \%$ paraformaldehyde in PBS, and then permeabilized in $0.5 \%$ Triton $\mathrm{X}-100$ in PBS. After treatment with $\mathrm{HCl} 2 \mathrm{~N}\left(30 \mathrm{~min}, 37^{\circ} \mathrm{C}\right)$ and neutralization with Tris $\mathrm{HCl} 100 \mathrm{mM}$ pH 8.8, the cells were incubated in a blocking solution (1\% BSA, $0.05 \%$ Tween 20 in PBS). The $5 \mathrm{mC}$ labelling was performed with a primary monoclonal antibody against $5 \mathrm{mC}$ (clone 33D3, AbD Serotec by Biorad) and an Alexa-Fluor ${ }^{\circledR}$ 647-conjugated goat anti-mouse Ig secondary antibody (Invitrogen by Life Technologies). Cells were finally labelled in $5 \mu \mathrm{g} / \mathrm{mL}$ propidium iodide (PI) in PBS. All steps were performed at room temperature except when indicated.

The $5 \mathrm{mC}$ labelling was analyzed on a LSRII cytometer (BD Biosciences, Le Pont de Claix, France) using the BD FACSDiva software. After gating the cells according to their propidium iodide content in order to exclude debris, cell-doublets, aggregates or apoptotic cells, the means of fluorescence intensities (mfi) were recorded on at least 5000 cells. The $5 \mathrm{mC}$ mfis were reported to the mfis from control samples as indicated in the legends.

\section{DNA extraction and bisulfite treatment}

DNA was isolated from cultured KG1 cells using the DNeasy Blood and Tissue Kit on a QIACUBE automation system according to the manufacturer's specifications 
(Qiagen). DNA bisulfite conversion was performed on $1 \mu \mathrm{g}$ of DNA using the Epitect Plus DNA Bisulfite Kit according to the manufacturer's specifications (Qiagen). Cycling conditions on the PCR apparatus were defined by 3 cycles of denaturation/incubation with times/ temperatures set as follows: $5 \mathrm{~min}$ at $95^{\circ} \mathrm{C}$ to denature the DNA followed by a $60^{\circ} \mathrm{C}$ incubation for 25,85 and $175 \mathrm{~min}$ for each cycle. The clean-up step of bisulfiteconverted DNA was carried out on a QIACUBE automation system according to the manufacturer's specifications (Qiagen).

\section{Methyl specific high resolution melting experiments (MS-HRM)}

Primers, forward (F) and reverse (R), were designed using bisulfite-converted sequences of the promoters from the studied genes:

\begin{tabular}{|l|l|l|}
\hline \multicolumn{1}{l}{ Target } & Primer sequences & Position Refseq (NCBI) \\
\hline CDH1 & $\begin{array}{l}\text { F-GGAATTGTAAAGTATTTGTGAGTTTG } \\
\text { R-ACTCCAAAAACCCATAACTAACC }\end{array}$ & chr16: 68771204-6877133 (F/R) \\
\hline CDKN2B $B$ & $\begin{array}{l}\text { F-CGTTTTTAGTTGGGTTAAGGGGT } \\
\text { R-GTCCTAACATCTTTAAACAAACTTCCC }\end{array}$ & chr1: 3568567-3568661 (F/R) \\
\hline$T P 73$ & $\begin{array}{l}\text { F-GTTATATTTTTTGTTTTTTGGATTTTAAG } \\
\text { R-TTTCCTAACACCCGAATCTCTCCT }\end{array}$ & \\
\hline
\end{tabular}

The localization of the primers is reported in Supplementary Figures S8, S10 and S11.

The PCR reactions were performed as duplicates in a final volume of $15 \mu \mathrm{L}$ on $70 \mathrm{ng}$ of bisulfite converted DNA as follows: $2 \mathrm{~min}$ at $95^{\circ} \mathrm{C}$ to activate the "hot start" enzyme and 45 cycles at $95^{\circ} \mathrm{C}$ for $10 \mathrm{sec}$ and $58^{\circ} \mathrm{C}$ for $30 \mathrm{sec}$; followed by a high resolution fusion curve from $65^{\circ} \mathrm{C}$ to $90^{\circ} \mathrm{C}\left(0.2^{\circ} \mathrm{C}\right.$ step climb every $\left.10 \mathrm{sec}\right)$ to determine the specific Tm of each amplicon. Hypomethylation will translate into a lower $\mathrm{Tm}$ due to the transformation of unmethylated cytosines into uracils and thymidines after PCR. The MS-HRM PCR efficiency was higher than 90\%. Data analyses were performed using the Precision Melt Analysis software (Bio-Rad). The melting curve of unmethylated control DNA was subtracted from the melting curve of each sample for data analysis and representation. This transformation allows us to obtain an Area-UnderCurve (AUC) plot correlated to the methylation rate of each studied promoter. Fully methylated (FM) and fully unmethylated (FU) control DNA were obtained from Qiagen.

\section{Pyrosequencing experiments}

The preparative PCR with a biotinylated primer was performed on $20 \mathrm{ng}$ of bisulfite-converted DNA with Pyromark PCR Master Mix (Qiagen). Reactions were carried out in a final volume of $15 \mu \mathrm{L}$ as follows: $15 \mathrm{~min}$ at $95^{\circ} \mathrm{C}$ to activate the "hot start" enzyme and 45 cycles at $95^{\circ} \mathrm{C}$ for 30 sec, $56^{\circ} \mathrm{C}$ for $30 \mathrm{sec}$ and $72^{\circ} \mathrm{C}$ for $30 \mathrm{sec}$; followed by a final extension at $72^{\circ} \mathrm{C}$ for $10 \mathrm{~min}$. After denaturation of PCR products and binding of biotinylated-strands on sepharose coated streptavidine beads, pyrosequencing was performed on a Pyromark Q24 according to the manufacturer's specifications (Qiagen). Amplification and sequencing primers have been designed and manufactured by Qiagen under the following referenced assays, except for LINE-1 and AluSc primers that were manually designed.

\section{Primers for Pyrosequencing}

\begin{tabular}{|c|c|c|}
\hline Target & Primer sequences & Position Refseq (NCBI) \\
\hline $\mathrm{CDH1}$ & Hs_CDH1_02_PMPyroMarkCPGassay PM00171948 & chr16: $68772100-68772129$ \\
\hline$C D K N 2 B$ & Hs_CDKN2B_01_PMPyroMarkCPGassay PM00039893 & chr9: $22008945-22008981$ \\
\hline LINE-1 & $\begin{array}{l}\text { sense 5'-GGGTTTATTTTATTAGGGAGTGTTAGAT-3' } \\
\text { reverse-biotin 5'-AAAAAAACTCCCTAACCCCTTAC-3' } \\
\text { sequencing 5'-AGTGGGAGTAGGTTAGT-3' }\end{array}$ & Repeated sequences \\
\hline AluSc & $\begin{array}{l}\text { sense 5'-AGAGATAGAGATTATTTTGGTTAATATGG-3' } \\
\text { reverse-biotin 5'-AATTCAAACCATTCTCCTACCTCAAC-3' } \\
\text { sequencing 5'-ATTAAAAATATAAAAATTAGTTGG-3' }\end{array}$ & Repeated sequences \\
\hline TP73 & Hs_TP73_02_PMPyroMarkCPGassay PM00084868 & chr1: $3607097-3607129$ \\
\hline
\end{tabular}

Localization of the primers is reported in Supplementary Figures S8, S10 and S11. 


\section{$\gamma H 2 A X$ phosphorylation and cell cycle analysis measurements}

Seventy-two hours after treatment, $5 \times 10^{5}$ cells were collected, fixed and permeabilized with DNA Prep LPR (6607055, Beckman Coulter), incubated with an Alexa Fluor 647-conjugated anti- $\gamma \mathrm{H} 2 \mathrm{AX}$ phosphorylated (Ser139) antibody from Biolegend (613408, London, United Kingdom) at a 1:150 dilution in PBS 1\% BSA for $45 \mathrm{~min}$. Cells were then washed with PBS 1\% BSA, and incubated for 60 min with DNA Prep Stain solution (Beckman Coulter) to stain the DNA. Cells were then analyzed with a Becton Dickinson LSRII flow cytometer. ModFit LT ${ }^{\mathrm{TM}} 3.0$ software was used to analyze the repartition of the cells along cell cycle phases, i.e., G0/G1, $\mathrm{S}$ and $\mathrm{G} 2 / \mathrm{M}$. For the $\gamma \mathrm{H} 2 \mathrm{AX}$ phosphorylation analysis, cells incubated with vehicle, or electroporated with the control siRNA, were used to define a fluorescent threshold for cells expressing the phosphorylated form of $\gamma \mathrm{H} 2 \mathrm{AX}$.

\section{Cell survival}

Briefly, 2x10 KG1 cells, previously treated for 72 $\mathrm{h}$ with either various doses of DAC, DNMT1 siRNAs or both, were seeded in 6 well plates. $96 \mathrm{~h}$ later cell viability was assessed via the Trypan Blue (Sigma Aldrich) exclusion method using a Cellometer ${ }^{\mathrm{TM}}$ from Ozyme (St Quentin Yvelines, France).

\section{Genome-wide methylation profiling using CpG microarrays}

DNA quantitation was measured using the QuantiT ${ }^{\mathrm{TM}}$ dsDNA Broad-Range Assay Kit (Life Technologies) according to the manufacturer's instruction. $1 \mu \mathrm{g}$ of DNA was bisulfite-converted using the EpiTect Bisulfite Conversion Kit (Qiagen). The Infinium ${ }^{\circledR} 450 \mathrm{~K}$ Methylation BeadChip (Illumina Inc., San Diego, CA, USA) was used for genome-wide methylation analysis. The experimental protocol was followed according to the manufacturer's instructions using $200 \mathrm{ng}$ DNA of each bisulfite-converted sample. Bead Chips were scanned using the Illumina ${ }^{\mathbb{B}}$ iScan system. The methylation level of each $\mathrm{CpG}$ site was calculated as the methylation beta value using the intensities between methylated and unmethylated probes ( $\beta$-value $=$ Methylated probe intensity $(\mathrm{M}) /($ Unmethylated probe intensity (U) + Methylated probe intensity $(\mathrm{M})+100)$ as defined by Illumina. Data were extracted using the Genome Studio software version 2011.1, Methylation module version 1.9.0 (Illumina Inc.) without any normalization steps. As quality control, Infinium I/II shift correction and data normalization was performed using a refined version of an in-house developed pipeline based on subset quantile normalization [45]. Unsupervised hierarchical clustering was performed using $\beta$-values for distance calculation and the "Ward" agglomerative hierarchical clustering method as distance measure minimizing the total within- cluster variance using squared Euclidean distances. The differentially methylated genes between Group1 and Group2 were analysed by the Ingenuity Pathways Analysis ${ }^{\circledR}$ tool according to the number of deregulated $\mathrm{CpG}$ sites in the genes TSS. The most enriched canonical pathways were considered significant with a threshold $p$-value $<0.01$. The value of ratio is calculated by dividing the number of deregulated genes in a specific pathway by the total number of genes that constitute this pathway. All the data generated in this genome-wide analysis come from three biological independent experiments for each control and treatment analyzed.

\section{Statistical analysis}

A minimum of two biologically independent experiments were performed to generate mean values $+/-$ standard deviation (SD). In the case of global methylation measurement through flow cytometry, cell cycle analysis, and $\gamma \mathrm{H} 2 \mathrm{AX}$ phosphorylation, a minimum of 4 replicates were compiled due to the small variations between the various treatments. For the $p$-value calculations, and since more than two conditions had to be compared, one way ANOVA associated with the contrast method was used (SAS R9.3). One star * refers to a $p$-value $\leq 0.05$, $* * \leq 0.01$ and $* * * \leq 0.001$. In the case of MS-HRM, the $p$-values were obtained from Tukey's post-hoc comparisons.

\section{ACKNOWLEDGMENT}

The authors thank Chantal Etievant and Jean-Marc Gregoire for helpful discussions.

\section{FUNDING}

This work was supported by Centre National de la Recherche Scientifique (CNRS) [ATIP to P.B.A.]; and Région Midi Pyrenées [Equipe d'Excellence and FEDER CNRS/Région Midi Pyrenées to P.B.A] and Fondation InNaBioSanté [to P.B.A.].

\section{Dedication}

Dedicated to the memory of M. Pierre Fabre (19262013), founder of the Pierre Fabre Laboratories and a visionary pharmacist.

\section{REFERENCES}

1. Bojang P Jr, Ramos KS. The promise and failures of epigenetic therapies for cancer treatment. Cancer Treatment Reviews. 2014; 40:153-169.

2. De Carvalho DD, You JS, Jones PA. DNA methylation and cellular reprogramming. Trends Cell Biol. 2010; 20:609-617. 
3. Robertson KD. DNA methylation and human disease. Nat Rev Genet. 2005; 6:597-610.

4. Baylin SB, Jones PA. A decade of exploring the cancer epigenome - biological and translational implications. Nat Rev Cancer. 2011; 11:726-734.

5. Fahy J, Jeltsch A, Arimondo PB. DNA methyltransferase inhibitors in cancer: a chemical and therapeutic patent overview and selected clinical studies. Expert Opin Ther Pat. 2012; 22:1427-1442.

6. Gros C, Fahy J, Halby L, Dufau I, Erdmann A, Gregoire J-M, Ausseil F, Vispé S, Arimondo PB. DNA methylation inhibitors in cancer: Recent and future approaches. Biochimie. 2012; 94:2280-2296.

7. Issa J-PJ. DNA Methylation as a Therapeutic Target in Cancer. Clinical Cancer Research. 2007; 13:1634-1637.

8. Wang Y, Cardenas H, Fang F, Condello S, Taverna P, Segar M, Liu Y, Nephew KP, Matei D. Epigenetic Targeting of Ovarian Cancer Stem Cells. Cancer Res. 2014; 74:4922-4936.

9. Singh V, Sharma P, Capalash N. DNA methyltransferase-1 inhibitors as epigenetic therapy for cancer. Curr Cancer Drug Targets. 2013; 13:379-399.

10. Tellez CS, Grimes MJ, Picchi MA, Liu Y, March TH, Reed MD, Oganesian A, Taverna P, Belinsky SA. SGI-110 and entinostat therapy reduces lung tumor burden and reprograms the epigenome. Int J Cancer. 2014; 135:2223-2231.

11. Christman JK. 5-Azacytidine and 5-aza-2'-deoxycytidine as inhibitors of DNA methylation: mechanistic studies and their implications for cancer therapy. Oncogene. 2002; 21:5483-5495.

12. Ghoshal K, Datta J, Majumder S, Bai S, Kutay H, Motiwala T, Jacob ST. 5-Aza-deoxycytidine induces selective degradation of DNA methyltransferase 1 by a proteasomal pathway that requires the KEN box, bromo-adjacent homology domain, and nuclear localization signal. Mol Cell Biol. 2005; 25:4727-4741.

13. Liu K, Wang YF, Cantemir C, Muller MT. Endogenous assays of DNA methyltransferases: Evidence for differential activities of DNMT1, DNMT2, and DNMT3 in mammalian cells in vivo. Mol Cell Biol. 2003; 23:2709-2719.

14. Maslov AY, Lee M, Gundry M, Gravina S, Strogonova N, Tazearslan C, Bendebury A, Suh Y, Vijg J. 5-aza-2'deoxycytidine-induced genome rearrangements are mediated by DNMT1. Oncogene. 2012; 31:5172-5179.

15. Biswal BK, Beyrouthy MJ, Hever-Jardine MP, Armstrong D, Tomlinson CR, Christensen BC, Marsit CJ, Spinella MJ. Acute hypersensitivity of pluripotent testicular cancer-derived embryonal carcinoma to low-dose 5-aza deoxycytidine is associated with global DNA Damageassociated p53 activation, anti-pluripotency and DNA demethylation. PLoS ONE. 2012; 7:e53003.

16. Liu J, Xie Y-S, Wang F-L, Zhang L-J, Zhang Y, Luo HS. Cytotoxicity of 5-Aza-2'-deoxycytidine against gastric cancer involves DNA damage in an ATM-P53 dependent signaling pathway and demethylation of P16INK4A. Biomedicine \& Pharmacotherapy. 2013; 67:78-87.

17. Patties I, Kortmann RD, Glasow A. Inhibitory effects of epigenetic modulators and differentiation inducers on human medulloblastoma cell lines. J Exp Clin Cancer Res. 2013; 32:27.

18. Wang L, Zhang Y, Li R, Chen Y, Pan X, Li G, Dai F, Yang J. 5-aza-2'-Deoxycytidine enhances the radiosensitivity of breast cancer cells. Cancer Biother Radiopharm. 2013; 28:34-44.

19. Szyf M. Targeting DNA methylation in cancer. Bull Cancer. 2006; 93:961-972.

20. Ting AH, Jair KW, Suzuki H, Yen RW, Baylin SB, Schuebel KE. Mammalian DNA methyltransferase 1: inspiration for new directions. Cell Cycle. 2004; 3:1024-1026.

21. Ting AH, Jair KW, Suzuki H, Yen RW, Baylin SB, Schuebel KE. CpG island hypermethylation is maintained in human colorectal cancer cells after RNAi-mediated depletion of DNMT1. NatGenet. 2004; 36:582-584.

22. De Carvalho Daniel D, Sharma S, You Jueng S, Su S-F, Taberlay Phillippa C, Kelly Theresa K, Yang X, Liang G, Jones Peter A. DNA Methylation Screening Identifies Driver Epigenetic Events of Cancer Cell Survival. Cancer Cell. 2012; 21:655-667.

23. Rhee I, Bachman KE, Park BH, Jair KW, Yen RWC, Schuebel KE, Cui H, Feinberg AP, Lengauer C, Kinzler KW, Baylin SB, Vogelstein B. DNMT1 and DNMT3b cooperate to silence genes in human cancer cells. Nature. 2002; 416:552-556.

24. Robert MF, Morin S, Beaulieu N, Gauthier F, Chute IC, Barsalou A, MacLeod AR. DNMT1 is required to maintain CpG methylation and aberrant gene silencing in human cancer cells. Nat Genet. 2003; 33:61-65.

25. Su PH, Lin YW, Huang RL, Liao YP, Lee HY, Wang HC, Chao TK, Chen CK, Chan MW, Chu TY, Yu MH, Lai HC. Epigenetic silencing of PTPRR activates MAPK signaling, promotes metastasis and serves as a biomarker of invasive cervical cancer. Oncogene. 2013; 32:15-26.

26. Chik F, Szyf M. Effects of specific DNMT gene depletion on cancer cell transformation and breast cancer cell invasion; toward selective DNMT inhibitors. Carcinogenesis. 2011; 32:224-232.

27. Peters SL, Hlady RA, Opavska J, Klinkebiel D, Novakova S, Smith LM, Lewis RE, Karpf AR, Simpson MA, Wu L, Opavsky R. Essential Role for Dnmt1 in the Prevention and Maintenance of MYC-Induced T-Cell Lymphomas. Molecular and Cellular Biology. 2013; 33:4321-4333.

28. Ma DK, Guo JU, Ming GL, Song H. DNA excision repair proteins and Gadd45 as molecular players for active DNA demethylation. Cell Cycle. 2009; 8:1526-1531. 
29. Lakshmikuttyamma A, Scott SA, DeCoteau JF, Geyer CR. Reexpression of epigenetically silenced AML tumor suppressor genes by SUV39H1 inhibition. Oncogene. 2010; 29:576-588.

30. Schmelz K, Wagner M, Dörken B, Tamm I. 5-Aza-2'deoxycytidine induces p21WAF expression by demethylation of p73 leading to p53-independent apoptosis in myeloid leukemia. International Journal of Cancer. 2005; 114:683-695.

31. Ferguson AT, Vertino PM, Spitzner JR, Baylin SB, Muller MT, Davidson NE. Role of estrogen receptor gene demethylation and DNA methyltransferase.DNA adduct formation in 5-aza-2'deoxycytidine-induced cytotoxicity in human breast cancer cells. J Biol Chem. 1997; 272: 32260-32266.

32. Kiianitsa K, Maizels N. A rapid and sensitive assay for DNA-protein covalent complexes in living cells. Nucleic Acids Res. 2013; 41:e104.

33. Burgess DJ, Doles J, Zender L, Xue W, Ma B, McCombie WR, Hannon GJ, Lowe SW, Hemann MT. Topoisomerase levels determine chemotherapy response in vitro and in vivo. Proc Natl Acad Sci U S A. 2008; 105:9053-9058.

34. Soubeyrand S, Pope L, Hache RJ. Topoisomerase IIalphadependent induction of a persistent DNA damage response in response to transient etoposide exposure. Mol Oncol. 2010; 4:38-51.

35. Orta ML, Calderon-Montano JM, Dominguez I, Pastor N, Burgos-Moron E, Lopez-Lazaro M, Cortes F, Mateos S, Helleday T. 5-Aza-2'-deoxycytidine causes replication lesions that require Fanconi anemia-dependent homologous recombination for repair. Nucleic Acids Res. 2013; 41:5827-5836.

36. Tsai HC, Li H, Van Neste L, Cai Y, Robert C, Rassool FV, Shin JJ, Harbom KM, Beaty R, Pappou E, Harris J, Yen RW, Ahuja N, et al. Transient low doses of DNA-demethylating agents exert durable antitumor effects on hematological and epithelial tumor cells. Cancer Cell. 2012; 21:430-446.
37. Mizuno S, Chijiwa T, Okamura T, Akashi K, Fukumaki Y, Niho Y, Sasaki H. Expression of DNA methyltransferases DNMT1, 3A, and 3B in normal hematopoiesis and in acute and chronic myelogenous leukemia. Blood. 2001; 97:1172-1179.

38. Patel K, Dickson J, Din S, Macleod K, Jodrell D, Ramsahoye B. Targeting of 5-aza-2'-deoxycytidine residues by chromatin-associated DNMT1 induces proteasomal degradation of the free enzyme. Nucleic Acids Res. 2010; 38:4313-4324.

39. Hagemann S, Kuck D, Stresemann C, Prinz F, Brueckner B, Mund C, Mumberg D, Sommer A. Antiproliferative effects of DNA methyltransferase 3B depletion are not associated with DNA demethylation. PLoS ONE. 2012; 7:e36125.

40. Cai Y, Geutjes EJ, de Lint K, Roepman P, Bruurs L, Yu LR, Wang W, van Blijswijk J, Mohammad H, de Rink I, Bernards R, Baylin SB. The NuRD complex cooperates with DNMTs to maintain silencing of key colorectal tumor suppressor genes. Oncogene. 2014; 33:2157-2168.

41. Han H, Yang X, Pandiyan K, Liang G. Synergistic re-activation of epigenetically silenced genes by combinatorial inhibition of DNMTs and LSD1 in cancer cells. PLoS ONE. 2013; 8:e75136.

42. Livak KJ, Schmittgen TD. Analysis of Relative Gene Expression Data Using Real-Time Quantitative PCR and the 2- $\Delta \Delta$ CT Method. Methods. 2001; 25:402-408.

43. Laemmli UK. Cleavage of structural proteins during the assembly of the head of bacteriophage T4. Nature. 1970; 227:680-685.

44. Desjobert C, El Maï M, Gérard-Hirne T, Guianvarc'h D, Carrier A, Pottier C, Arimondo PB, Riond J. Combined analysis of DNA methylation and cell cycle in cancer cells. Epigenetics. 2014 Dec; 22:1-10.

45. Touleimat $\mathrm{N}$, Tost J. Complete pipeline for Infinium $^{\circledR}$ Human Methylation 450K BeadChip data processing using subset quantile normalization for accurate DNA methylation estimation. Epigenomics. 2012; 4:325-341. 